\title{
Review of an Effective Dynamic Vibration Absorber for a Simply Supported Beam and Parametric Optimization to Reduce Vibration Amplitude
}

\author{
${ }^{1}$ S Pani, ${ }^{2}$ S.K Senapati, ${ }^{3}$ K.C Patra, ${ }^{4}$ P Nath \\ ${ }^{1}$ Assistant.Professor, \\ ${ }^{2}$ Professor In Mechanical Engineering Department, IGIT Sarang,(Govt Engineering College)Odisha,India \\ 3Assistant .Professor \\ 4Mtech scholar IGIT Sarang
}

\begin{abstract}
In this work theoretical natural frequencies and mode shape of the simply supported beam type main vibrating system ie used in many areas like bridges and double-beam structures is determined. Dynamic vibration absorber is designed and developed at one of the resonant frequencies of the main vibrating system. Natural frequencies and mode shapes of main vibrating system obtained theoretically and also by using FEA analysis. The system considered is essentially a modification of the conventional damped vibration absorber and consists of adding, in parallel, a subsidiary undamped absorber mass in addition to the damped absorber mass. Uses MATLAB to find optimize parameter to reduce the vibration amplitude. Also use ANSYS for FEA analysis of simply supported beam type main vibrating system. Development to test the performance of a damped and undamped vibration absorber for the simply supported beam type main system. The analysis clearly shows that it is possible to obtain an undamped antiresonance in a dynamic absorber system which exhibits a well-damped resonance. While the bandwidth of frequencies between the damped peaks is not significantly increased, the amplitudes of the main mass are considerably smaller within the operational range of the absorber. A total of 4 models are taken for consideration for the damped vibration absorber. By comparing in between those models, we came to know that model (C) gives better vibration suppression and also required less damping ratio for anti resonance.
\end{abstract}

Keywords: Tuned Vibration Absorber, Damped TVA, Damped Primary system, Optimum Damping ratio.

\section{LIST OF SYMBOLS}

Most of the symbols are defined as they occur in the thesis. Some of the most common symbols, which are repeatedly used, are listed below.

$\mathrm{E}=$ Young's modulus of elasticity of the beam

$\mathrm{I}=\mathrm{M} \mathrm{I}$ of the beam

$\rho=$ density of the beam

$x=$ distance from one of the ends of beam

$\mathrm{X}=$ amplitude of vibration

$\mathrm{A}=\mathrm{c} / \mathrm{s}$ area of the beam

$t=$ time independent variable

$\omega_{n}=$ natural frequency of the system

$k=$ stiffness of the spring

$X_{S t}=F_{0} / k_{1}=$ Frequency deflection of first mass

$\omega_{1}=k_{1} / m_{1}=$ natural frequency of main system alone

$\omega_{2}=k_{2} / m_{2}=$ natural frequency of the absorber system alone

$\mu=m_{2} / m_{1}=$ ratio of absorber mass to the main mass

$X_{s t}=\mathrm{F}_{0} / \mathrm{k}_{1}=$ Static deflection of the system

$\omega_{a}^{2}=\mathrm{k}_{2} / \mathrm{m}_{2}=$ Square of natural frequency of the absorber

$\omega_{n}^{2}=\mathrm{k}_{1} / \mathrm{m}_{1}=$ Square of natural frequency of main mass

$f=\omega_{\mathrm{a}} / \omega_{\mathrm{n}}=$ Ratio of natural frequencies

$\mathrm{g}=\omega / \omega_{\mathrm{n}}=$ Forced frequency ratio

$C=$ damping constant

$C_{C}=2 m_{2} \omega_{\mathrm{n}}=$ Critical damping constant 
$\zeta=C_{2} / C_{C}=$ Damping ratio

$f_{f}=$ favorable tuning frequency/natural frequency of main mass

$f_{0}=$ amplitude of the forcing function

$h=$ natural frequency of undamped absorber/natural frequency of main mass

$i=\sqrt{-1}$

$k_{1}=$ Spring constant of main spring

$k_{2}=$ Spring constant of undamped absorber

$k_{3}=$ Spring constant of damped absorber

$m_{1}=$ Magnitude of main system

$\mathrm{r}=$ wire radius of spring

$\mathrm{R}=$ coil radius of spring

$\mathrm{G}=$ modulus of rigidity

$\Phi=$ rod diameter

$\mathrm{W}=$ Suspended weight

$\mathrm{K}_{\mathrm{w}}=$ Wahl's correction factor

$\mathrm{c}=$ spring index

$\mathrm{FRF}=$ Frequency response function

\section{Review of Literature}

\section{LITERATURE REVIEW}

The TMD concept was first applied by Frahm in 1909 (Frahm, 1909) to reduce the rolling motion of ships as well as ship hull vibrations. A theory for the TMD was presented later in the paper by Ormondroyd and Den Hartog(1928),followed by a detailed discussion of optimal tuning and damping parameters in Den Hartog's book on mechanical vibrations(1940). The initial theory was applicable tofrahm's undamped SDOF system subjected to a sinusoidal force excitation.Brock(1946) tooka different approach which is quite clever, yet straightforward. No differentiation was needed. Basedon the results, he suggested the optimum damping ratio can be given for model A. Kelly mentioned optimize parameter for model $\mathrm{A}$ on his book'Fundamentals of Mechanical Vibrations(2000)'. Srinivasan give optimize parameter for a parallel damped dynamic vibrationabsorbers (1969). Kefu liu and Jieliu (2004) provide optimize parameter for modified modelA system. Extension of the theory to damped SDOF systems has been investigated by numerous researchers.

Active control devices operate by using an external power supply. Therefore, they are more efficient than passive control devices. However the problems such as insufficient control-force capacity and excessive power demands encountered by current technology in the context of structural control against earthquakes are unavoidable and need to be overcome. Recently a new control approach-semiactive control devices, which combine the best features of both passive and active control devices, is very attractive due to their low power demand and inherent stability. The earlier papers involving SATMDs may traced to 1983.
Hrovatet al.(1983) presented SATMD, a TMD with time varying controllable damping.Under identical conditions, the behaviour of a structure equipped with SATMD instead of TMD is significantly improved. The control design of SATMD is less dependent on related parameters (e.g, mass ratios, frequency ratios and so on), so that there greater choices in selecting them. The first mode response of a structure with TMD tuned to the fundamental frequency of the structure can be substantially reduced but, in general, the higher modal responses may only be marginally suppressed or even amplified. To overcome the frequency-related limitations of TMDs, more than one TMD in a given structure, each tuned to a different dominant frequency, can be used. The concept of multiple tuned mass dampers (MTMDs) together with an optimization procedure was proposed by Clark (1988). Since, then, a number of studies have been conducted on the behaviour of MTMDs a doubly tuned mass damper (DTMD), consisting of two masses connected in series to the structure was proposed (Setareh 1994). In this case, two different loading conditions were considered: harmonic excitation and zero-mean white-noise random excitation, and the efficiency of DTMDs on response reduction was evaluated. Analytical results show that DTMDs are more efficient than the conventional single mass TMDs over the whole range of total mass ratios, but are only slightly more efficient than TMDs over the practical range of mass ratios (0.01$0.05)$.

Recently, numerical and experimental studies have been carried out on the effectiveness of TMDs in reducing seismic response of structures [for instance, Villaverde(1994)]. In Villaverde(1994), three different structures were studied, in which the first one is a 2D two story shear building the second is a three-dimensional (3D) one-story frame building, and the third is a $3 \mathrm{D}$ cable-stayed bridge, using nine 
different kinds of earthquake records. Numerical and experimental results show that the effectiveness of TMDs on reducing the response of the same structure during different earthquakes, or of different structures during the same earthquake is significantly different; some cases give good performance and some have little or even no effect. This implies that there is a dependency of the attained reduction in response on the characteristics of the ground motion that excites the structure. This response reduction is large for resonant ground motions and diminishes as the dominant frequency of the ground motion gets further away from the structure's natural frequency to which the TMD is tuned. Also, TMDs are of limited effectiveness under pulse-like seismic loading. Multiple passive TMDs for reducing earthquake induced building motion. Allen J. Clark

(1988). In this paper a methodology for designing multiple tuned mass damper for reducingbuilding response motion has been discussed. The technique is based on extending Den Hartog work from a single degree of freedom to multiple degrees of freedom. Simplified linear mathematical models were excited by $1940 \mathrm{El}$ Centro earthquake and significant motion reduction was achieved using the design technique. Performance of tuned mass dampers under wind loads K. C. S. Kwok et al. (1995). The performance of both passive and active tuned mass damper (TMD) systems can be readily assessed by parametric studies which have been the subject of numerous research.. Few experimental verifications of TMD theory have been carried out, particularly those involving active control, but the results of those experiments generally compared well with those obtained by parametric studies. Despite some serious design constraints, a number of passive and active tuned mass damper systems have been successfully installed in tall buildings and other structures to reduce the dynamic response due to wind and earthquakes.

Mitigation of response of high-rise structural systems by means of optimal tuned mass damper. A.N Blekherman(1996). In this paper a passive vibration absorber has been proposed to protect high-rise structural systems from earthquake damages. A structure is modelled by one-mass and nmass systems (a cantilever scheme). Damping of the structure and absorber installed on top of it is represented by frequency independent one on the base of equivalent visco-elastic model that allows the structure with absorber to be described as a system with non-proportional internal friction. A ground movement is modelled by an actuator thatproduces vibration with changeable amplitude and frequency. To determine the optimum absorber parameters, an optimization problem, that is a minmaxone, was solved by using nonlinear programming technique ( the Hooke-Jeves method).
Survey of actual effectiveness of mass damper systems installed in buildings.T.Shimazu and H. Araki (1996). In this paper the real state of the implementation of mass damper systems, the effects of these systems were clarified based on various recorded values in actual buildings against both wind and earthquake. The effects are discussed in relation with the natural period of buildings equipped with mass damper systems, the mass weight ratios to building weight, wind force levels and earthquake ground motion levels.

A method of estimating the parameters of tuned mass dampers for seismic applications. FahimSadeket al. (1997). In this paper the optimum parameters of TMD that result in considerable reduction in the response of structures to seismic loading has been presented. The criterion that has been used to obtain the optimum parameters is to select for a given mass ratio, the frequency and damping ratios that would result in equal and large modal damping in the first two modes of vibration. The parameters are used to compute the response of several single and multi-degree of freedom structures with TMDs to different earthquake excitations. The results show that the use of the proposed parameters reduces the displacement and acceleration responses significantly. The method can also be used for vibration control of tall buildings using the so-called mega-substructure configuration, where substructures serve as vibration absorbers for the main structure.

Structural control: past, present, and future G. W. Housneret al.(1996).This paper basically provides a concise point of departure for those researchers and practitioners who wishing to assess the current state of the art in the control and monitoring of civil engineering structures; and provides a link between structural control and other fields of control theory, pointing out both differences and similarities, and points out where future research and application efforts are likely to prove fruitful.

Structural vibration of tuned mass installed three span steel box bridge. Byung-Wan Jo et al (2001).To reduce the structural vibration of a three span steel box bridge a three axis two degree of freedom system is adopted to model the mass effect of the vehicle and the kinetic equation considering the surface roughness of the bridge is derived based on Bernoulli-Euler beam ignoring the torsional DOF. The effects of TMD on steel box bridge shows that it is not effective in reducing the maximum deflection, but it efficiently reduces the free vibration of the bridge. It proves that the TMD is effective in controlling the dynamic amplitude rather than the maximum static deflection.

Optimal placement of multiple tuned mass dampers for seismic structures. Genda Chen et al.(2001). In this paper effects of a tuned mass 
damper on the modal responses of a six-story building structure are studied. Multistage and multimode tuned mass dampers are then introduced. Several optimal location indices are defined based on intuitive reasoning, and a sequential procedure is proposed for practical design and placement of the dampers in seismically excited building structures. The proposed procedure is applied to place the dampers on the floors of the six-story building for maximum reduction of the accelerations under a stochastic seismic load and 13 earthquake records. Numerical results show that the multiple dampers can effectively reduce the acceleration of the uncontrolled structure by $10-25 \%$ more than a single damper. Time-history analyses indicate that the multiple dampers weighing $3 \%$ of total structural weight can reduce the floor acceleration up to $40 \%$.

Seismic effectiveness of tuned mass dampers for damage reduction of structures. T. Pinkaew et al.(2002).The effectiveness of TMD using displacement reduction of the structure is found to be insufficient after yielding of the structure, damage reduction of the structure is proposed instead. Numerical simulations of a 20-storey reinforced concrete building modelled as an equivalent inelastic single-degree-of-freedom (SDOF) system subjected to both harmonic and the 1985 Mexico City (SCT) ground motions are considered. It is demonstrated that although TMD cannot reduce the peak displacement of the controlled structure after yielding, it can significantly reduce damage to the structure. In addition, certain degrees of damage protection and collapse prevention can also be gained from the application of TMD. Tuned Mass Damper Design for Optimally Minimizing Fatigue Damage. Hua-Jun Li et al.(2002). This paper considers the environmental loading to be a long-term nonstationary stochastic process characterized by a probabilistic power spectral density function. One engineering technique to design a TMD under a long-term random loading condition is for prolonging the fatigue life of the primary structure.

Seismic structural control using semi-active tuned mass dampers. Yang Runlin et al.(2002).This paper focuses on how to determine the instantaneous damping of the semi-active tuned mass damper with continuously variable damping. An off-and- towardsequilibrium (OTE) algorithm is employed to examine the control performance of the structure/SATMD system by considering damping as an assumptive control action. Two numerical simulations of a fivestorey and a ten-storey shear structures with a SATMD on the roof are conducted. The effectiveness on vibration reduction of MDOF systems subjected to seismic excitations is discussed

Structural vibration suppression via active/passive techniques.Devendra P. Garg et al.(2003). The advances made in the area of vibration suppression via recently developed innovative techniques (for example, constrained layer damping (CLD) treatments) applied to civilian and military structures are investigated. Developing theoretical equations that govern the vibration of smart structural systems treated with piezo-magnetic constrained layer damping (PMCLD) treatments and developing innovative surface damping treatments using micro-cellular foams and active standoff constrained layer (ASCL) treatments. The results obtained from the above and several other vibration suppression oriented research projects being carried out under the ARO sponsorship are also included in this study.

Performance of a five-storey benchmark model using an active tuned mass damper and a fuzzy controller.BijanSamali, Mohammed AlDawod(2003). This paper describes the performance of a five-storey benchmark model using an active tuned mass damper (ATMD), where the control action is achieved by a Fuzzy logic controller (FLC) under earthquake excitations. The advantage of the Fuzzy controller is its inherent robustness and ability to handle any non-linear behaviour of the structure. The simulation analysis of the five-storey benchmark building for the uncontrolled building, the building with tuned mass damper (TMD), and the building with ATMD with Fuzzy and linear quadratic regulator (LQR) controllers has been reported, and comparison between Fuzzy and LQR controllers is made. In addition, the simulation analysis of the benchmark building with different values of frequency ratio, using a Fuzzy controller is conducted and the effect of mass ratio, on the fivestorey benchmark model using the Fuzzy controller has been studied.

Behaviour of soil-structure system with tuned mass dampers during near-source earthquakes. NawawiChouw(2004). In this paper the influence of a tuned mass damper on the behaviour of a frame structure during near-source ground excitations has been presented. In the investigation the effect of soilstructure interaction is considered, and the natural frequency of the tuned mass damper is varied. The ground excitations used are the ground motion at the station SCG and NRG of the 1994 Northridge earthquake. The investigation shows that the soilstructure interaction and the characteristic of the ground motions may have a strong influence on the effectiveness of the tuned mass damper. But in order to obtain a general conclusion further investigations are necessary.

Wind Response Control of Building with Variable Stiffness Tuned Mass Damper Using Empirical Mode Decomposition Hilbert Transform NadathurVaradarajan et al.(2004).The effectiveness of a novel semi-active variable stiffness-tuned mass damper $\sim$ SAIVS-TMD! for the response control of a 
wind-excited tall benchmark building is investigated in this study. The benchmark building considered is a proposed 76-story concrete office tower in Melbourne, Australia. Across wind load data from wind tunnel tests are used in the present study. The objective of this study is to evaluate the new SAIVSTMD system, that has the distinct advantage of continuously retuning its frequency due to real time control and is robust to changes in building stiffness and damping. The frequency tuning of the SAIVSTMD is achieved based on empirical mode decomposition and Hilbert transform instantaneous frequency algorithm developed by the writers. It is shown that the SAIVS-TMD can reduce the structural response substantially, when compared to the uncontrolled case, and it can reduce the response further when compared to the case with TMD. Additionally, it is shown the SAIVS-TMD reduces response even when the building stiffness changes by $15 \%$.

Effect of soil interaction on the performance of tuned mass dampers for seismic applications. A. Ghosha, B. Basu(2004). The properties of the structure used in the design of the TMD are those evaluated considering the structure to be of a fixedbase type. These properties of the structure may be significantly altered when the structure has a flexible base, i.e. when the foundation of the structure is supported on compliant soil and undergoes motion relative to the surrounding soil. In such cases, it is necessary to study the effects of soil-structure interaction (SSI) while designing the TMD for the desired vibration control of the structure. In this paper, the behaviour of flexible-base structures with attached TMD, subjected to earthquake excitations has been investigated. Modified structural properties due to SSI has been covered in this paper.

Optimal design theories and applications of tuned mass dampers. Chien-Liang Lee et al.(2006).An optimal design theory for structures implemented with tuned mass dampers (TMDs) is proposed in this paper. Full states of the dynamic system of multiple-degree-of-freedom (MDOF) structures, multiple TMDs (MTMDs) installed at different stories of the building, and the power spectral density (PSD) function of environmental disturbances are taken into account. The optimal design parameters of TMDs in terms of the damping coefficients and spring constants corresponding to each TMD are determined through minimizing a performance index of structural responses defined in the frequency domain. Moreover, a numerical method is also proposed for searching for the optimal design parameters of MTMDs in a systematic fashion such that the numerical solutions converge monotonically and effectively toward the exact solutions as the number of iterations increases. The feasibility of the proposed optimal design theory is verified by using a SDOF structure with a single TMD (STMD), a five-DOF structure with two TMDs, and a ten-DOF structure with a STMD.

Optimum design for passive tuned mass dampers using viscoelastic materials. I Saidi, A D Mohammed et al.(2007). This paper forms part of a research project which aims to develop an innovative cost effective Tune Mass Damper (TMD) using viscoelastic materials. Generally, a TMD consists of a mass, spring, and dashpot which is attached to a floor to form a two-degree of freedom system. TMDs are typically effective over a narrow frequency band and must be tuned to a particular natural frequency. The paper provides a detailed methodology for estimating the required parameters for an optimum TMD for a given floor system. The paper also describes the process for estimating the equivalent viscous damping of a damper made of viscoelastic material. Finally, a new innovative prototype viscoelastic damper is presented along with associated preliminary results.

Semi-active Tuned Mass Damper for Floor Vibration Control .Mehdi Setareh et al.(2007). A semi-active magneto-rheological device is used in a pendulum tuned mass damper PTMD system to control the excessive vibrations of building floors. This device is called semi-active pendulum tuned mass damper SAPTMD. Analytical and experimental studies are conducted to compare the performance of the SAPTMD with its equivalent passive counterpart. An equivalent single degree of freedom model for the SAPTMD is developed to derive the equations of motion of the coupled SAPTMD-floor system. A numerical integration technique is used to compute the floor dynamic response, and the optimal design parameters of the SAPTMD are found using an optimization algorithm. Effects of off-tuning due to the variations of the floor mass on the performance of the PTMD and SAPTMD are studied both analytically and experimentally. From this study it can be concluded that for the control laws considered here an optimum SAPTMD performs similarly to its equivalent PTMD, however, it is superior to the PTMD when the floor is subjected to off-tuning due to floor mass variations from sources other than human presence.

Seismic Energy Dissipation of Inelastic Structures with Tuned Mass Dampers. K. K. F. Wong(2008).The energy transfer process of using a tuned mass damper TMD in improving the ability of inelastic structures to dissipate earthquake input energy is investigated. Inelastic structural behaviour is modelled by using the force analogy method, which is the backbone of analytically characterizing the plastic energy dissipation in the structure. The effectiveness of TMD in reducing energy responses is also studied by using plastic energy spectra for various structural yielding levels. Results show that 
the use of TMD enhances the ability of the structures to store larger amounts of energy inside the TMD that will be released at a later time in the form of damping energy when the response is not at a critical state, thereby increasing the damping energy dissipation while reducing the plastic energy dissipation. This reduction of plastic energy dissipation relates directly to the reduction of damage in the structure.

Dynamic analysis of space structures with multiple tuned mass dampers. Y.Q. Guo and W.Q.Chen(2008). Formulations of the reverberation matrix method (RMM) are presented for the dynamic analysis of space structures with multiple tuned mass dampers (MTMD). The theory of generalized inverse matrices is then employed to obtain the frequency response of structures with and without damping, enabling a uniform treatment at any frequency, including the resonant frequency. For transient responses, the Neumann series expansion technique as suggested in RMM is found to be confined to the prediction of accurate response at an early time. The artificial damping technique is employed here to evaluate the medium and long time response of structures. The free vibration, frequency response, and transient response of structures with MTMD are investigated by the proposed method through several examples. Numerical results indicate that the use of MTMD can effectively alter the distribution of natural frequencies as well as reduce the frequency/transient responses of the structure. The high accuracy, lower computational cost, and uniformity of formulation of RMM are also highlighted in this paper.

Exploring the performance of a nonlinear tuned mass damper. Nicholas A. Alexander and Frank Schilder (2009).In this the performance of a nonlinear tuned mass damper (NTMD), which is modelled as a two degree of freedom system with a cubic nonlinearity has been covered. This nonlinearity is physically derived from a geometric configuration of two pairs of springs. The springs in one pair rotate as they extend, which results in a hardening spring stiffness. The other pair provides a linear stiffness term. In this paper an extensive numerical study of periodic responses of the NTMD using the numerical continuation software AUTO has been done. Two techniques have been employed for searching the optimal design parameters; optimization of periodic solutions and parameter sweeps. In this paper the writers have discovered a family of resonance curves for vanishing linear spring stiffness.

Application of semi-active control strategies for seismic protection of buildings with $\mathrm{MR}$ dampers. Maryam Bitaraf et al.(2010).Magnetorheological (MR) dampers are semi-active devices that can be used to control the response of civil structures during seismic loads. They are capable of offering the adaptability of active devices and stability and reliability of passive devices. One of the challenges in the application of the MR dampers is to develop an effective control strategy that can fully exploit the capabilities of the MR dampers. This study proposes two semi-active control methods for seismic protection of structures using MR dampers. The first method is the Simple Adaptive Control method which is classified as a direct adaptive control method. The controller developed using this method can deal with the changes that occur in the characteristics of the structure because it can modify its parameters during the control procedure. The second controller is developed using a genetic-based fuzzy control method. In particular, a fuzzy logic controller whose rule base determined by a multiobjective genetic algorithm is designed to determine the command voltage of MR dampers.

Vibration control of seismic structures using semi-active friction multiple tuned mass dampers. Chi-Chang Lin et al.(2010) There is no difference between a friction-type tuned mass damper and a dead mass added to the primary structure if static friction force inactivates the mass damper. To overcome this disadvantage, this paper proposes a novel semi-active friction-type multiple tuned mass damper (SAF-MTMD) for vibration control of seismic structures. Using variable friction mechanisms, the proposed SAF-MTMD system is able to keep all of its mass units activated in an earthquake with arbitrary intensity. A comparison with a system using passive friction-type multiple tuned mass dampers (PF-MTMDs) demonstrates that the SAF-MTMD effectively suppresses the seismic motion of a structural system, while substantially reducing the strokes of each mass unit, especially for a larger intensity earthquake.

\section{AIM AND SCOPE OF THIS WORK}

However, despite of its many advantages for DVA it can be effectively used only in the case of constant speed machines. But in many practical applications the excitation frequency may not be constant: In such cases, the concept of DVA may not be applicable because the absorber is designed with a frequency matches the excitation frequency. For a wide range of excitation frequencies either the mass or stiffness of the spring has made to be varied according to the variation in its excitation frequency. 1. To improve the effectiveness of the conventional absorber by suitable modification, or

2. To invent entirely different and better devices in the hope of replacing the conventional absorber.

Gyroscopic vibration absorbers and impact dampers are but a few of the new devices that belong to the latter group. However, the only modification considered so far in the former group is the addition 
of damping to the absorber mass. The purpose of this paper is to examine a further modification of the conventional absorber. Such a modification consists of adding, in parallel, a subsidiary undamped absorber mass in addition to the damped absorber mass. The system considered is shown in below Fig. The analysis that follows consists mainly of:

1. the derivation of the governing equations of motion, and

2. derivation of the condition for the amplitude of the main mass to be independent of the damping ratio $C / C c$.

The latter condition provides the frequencies at which the amplitudes of the main mass are independent of the damping ratio $\mathrm{C} / \mathrm{Cc}$ - In addition, for the particular case of practical interest (i.e., when the absorber masses and the springs have the same value), the so-called favorable tuning (i.e., the tuning frequency at which the absolute value of the amplitudes independent of $C / C c$ is the same) has been determined in the form of a simple equation. Under this favorable tuning, the mass ratio required to provide the greatest spread between the frequencies is determined.Also, the equation which provides the optimum damping ratio (i.e., the ratio $C / C c$ at which the slope of the response curve is zero) has been derived.

Theoretical analysis of continuous beam vibration:

\section{THEORETICAL ANALYSIS}

The general differential equation governing transverse vibration of a Euler-bernouli beam is given as

$$
E I \frac{\partial^{4} X}{\partial x^{4}}(x, t)+\rho A \frac{\partial^{2} X}{\partial t^{2}}(x, t)=f(x, t)
$$

For free, $f(x, t)=0$, vibration, and so the equation of motion becomes

$$
C^{2} \frac{\partial^{4} X}{\partial x^{4}}(x, t)+\frac{\partial^{2} X}{\partial t^{2}}(x, t)=0
$$

Where $c=\sqrt{\frac{E I}{\rho A}}$

The free-vibration solution can be found using the method of separation of variables as

$$
\mathrm{X}(x, t)=\mathrm{X}(x) \mathrm{T}(t)
$$

Substituting Eq. (2) into Eq. (1) and rearranging leads to

$$
\frac{C^{2}}{X(x)} \frac{\partial^{4} X(x)}{\partial x^{4}}=-\frac{1}{T(t)} \frac{\partial^{2} T(t)}{\partial t^{2}}=a=\omega^{2}
$$

Where $a=\omega^{2}$ is a positive constant . Eq. (3) can be written as two equations:

Where

$$
\frac{\partial^{4} X(x)}{\partial x^{4}}-\beta^{4} X(x)=0
$$

The solution of Eq. (5) can be expressed as

$$
\beta^{4}=\frac{\omega^{2}}{c^{2}}=\frac{\rho A \omega^{2}}{E I}
$$

$$
\begin{gathered}
\mathrm{T}(\mathrm{t})=\mathrm{A} \cos \omega \mathrm{t}+\mathrm{B} \sin \omega \mathrm{t} \ldots \ldots \ldots \ldots \ldots \ldots \ldots \ldots \ldots \ldots \ldots \ldots \ldots \ldots \ldots \ldots \ldots \ldots \ldots \\
\mathrm{X}(x)=C_{1} \cos \beta x+C_{2} \sin \beta x+C_{3} \cosh \beta x+C_{4} \sinh \beta x
\end{gathered}
$$

Where $\mathrm{C}_{1}, \mathrm{C}_{2}, \mathrm{C}_{3}$ and $\mathrm{C}_{4}$ ineach case, are different constants. The constants $\mathrm{C}_{1}, \mathrm{C}_{2}, \mathrm{C}_{3}$ and $\mathrm{C}_{4}$ can be found from the boundary conditions. The natural frequencies of the beam are computed from Eq. (5) as

$$
\omega=\beta^{2} \sqrt{\frac{E I}{\rho A}}=(\beta l)^{2} \sqrt{\frac{E I}{\rho A l^{4}}}
$$

The function $X(x)$ is known as the normal mode or characteristic function of the beam and $\omega$ is called the natural frequency of vibration. For any beam, there will be an infinite number of normal modes with one natural frequency associated with each Deflection $=X=0$, Bending moment $=E I \frac{\partial^{2} X}{\partial x^{2}}=0$ at both ends. normal mode. The unknown constants to in Eq. (7) and the value ${ }_{\beta}$ of in Eq. (8) can be determined from the boundary conditions of the beam as indicated below.

Boundary condition for a Simply supported (pinned) end: 


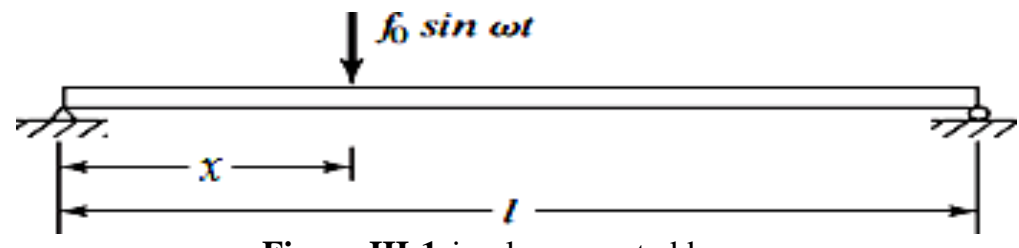

Figure III-1simply supported beam

After utilizing the above boundary condition for simply supported beam vibration analysis, we got the below result as shown in table 3.1 .

Table 3.1First four natural frequency for different modes of vibrating simply supported beam.

\begin{tabular}{|c|c|c|}
\hline $\begin{array}{l}\text { End conditions } \\
\text { OfBeam }\end{array}$ & $\begin{array}{l}\text { Frequency } \\
\text { Equation }\end{array}$ & Value of $\beta_{n} l$ \\
\hline Pinned-Pinned & $\sin \beta_{n} l=0 \quad X_{n}(x)=C_{n}\left[\sin \beta_{n} x\right]$ & $\begin{array}{l}\beta_{1} l=\pi \\
\beta_{2} l=2 \pi \\
\beta_{4} l=3 \pi \\
\beta_{3} l=4 \pi\end{array}$ \\
\hline
\end{tabular}

a. Undamped Vibration Absorbers:

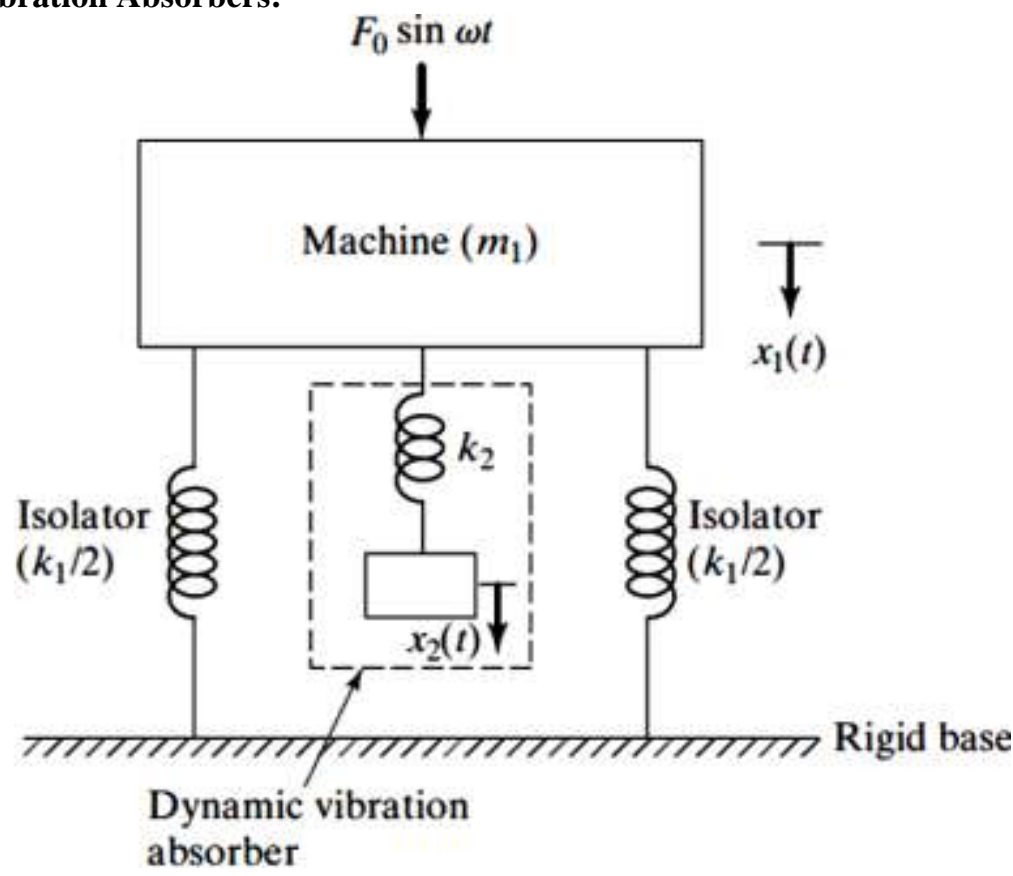

Figure III-2Undamped dynamic vibration absorber

The dynamic vibration absorbers, in the form of dumbbell-shaped devices are hung from transmission lines to mitigate the fatigue effects of wind inducedvibration.

The equations of motion of the masses $m_{1}$ and $m_{2}$ are

$$
\begin{array}{r}
m_{1} \ddot{x_{1}}+k_{1} x_{1}+k_{2}\left(x_{1}-x_{2}\right)=F_{0} \sin \omega \mathrm{t} \\
m_{2} \ddot{x_{2}}+k_{2}\left(x_{2}-x_{1}\right)=0 .
\end{array}
$$

By assuming harmonic solution,

$$
X_{j}(t)=X_{j} \sin \omega \mathrm{t}, \quad j=1,2
$$

we can obtain the steady-state amplitudes of the masses $m_{1}$ and $m_{2}$ as

$$
\frac{X_{2}}{X_{s t}}=\frac{\left[1-\frac{\omega^{2}}{\omega_{2}^{2}}\right]}{\frac{\omega_{s t}^{4}}{\omega_{1}^{2} \omega_{2}^{2}}-\left[(1+\mu) \frac{\omega^{2}}{\omega_{1}^{2}}+\frac{\omega^{2}}{\omega_{2}^{2}}\right]+1}
$$


Therefore there are two values of $\omega$ for which these expressions vanish.

$$
\left(\frac{\omega}{\omega_{2}}\right)^{2}=\left(1+\frac{\mu}{2}\right) \pm \sqrt{\mu+\frac{\mu^{2}}{4}}
$$

The addition of a vibration absorber is meaningful, if the main system is at resonance or atleast near to it. Under these condition we have $\omega_{1}=\omega$. But for the absorber to be effective, we have $\omega_{2}=\omega$. Therefore for the effectiveness of the absorber to be obtained,

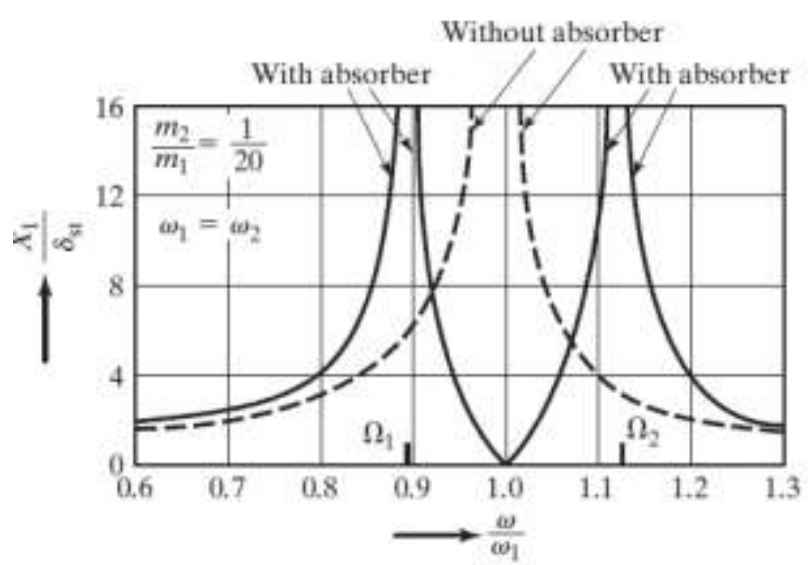

Figure III-3 Effect of undamped vibration absorber on the response of machine.

There is many combination of $\mathrm{K}_{2}$ and $\mathrm{M}_{2}$, but when $\mathrm{K}_{2}$ is small $\mathrm{X}_{2}$ is large, But for practical consideration $X_{2}<X_{1} / 2$. It cannot be so high. If $K_{2}$ is large, $\mathrm{m}_{2}$ is also large. Which make again a bulky system. So a compromise will make by taking proper $\mathbf{b}$. we have to $\omega_{2}=\omega_{1}$ or $k_{2} / m_{2}=k_{1} / m_{1}$.

Whenthe above condition is fulfilled, the absorber is known as tuned absorber.

When $\omega_{2}=\omega ; \quad \mathrm{X}_{2}=-\mathrm{F}_{0} / \mathrm{K}_{2}$

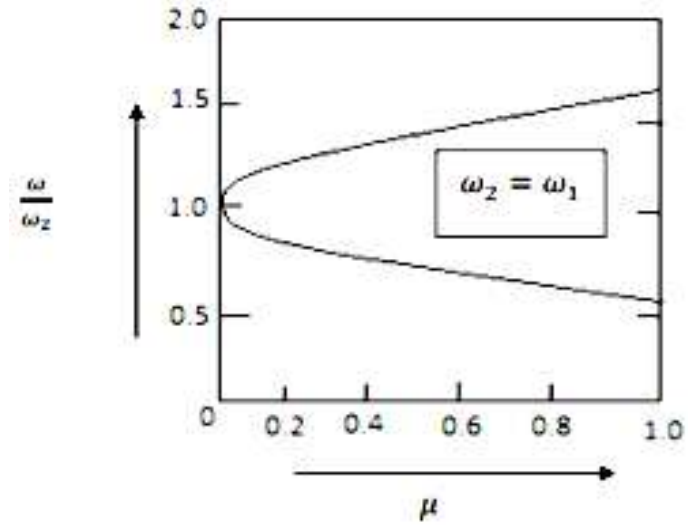

Figure III-4 Effect of mass ratio on resonant frequency.

\section{c. Undamped parallel dual mass dynamic Vibration Absorbers:}

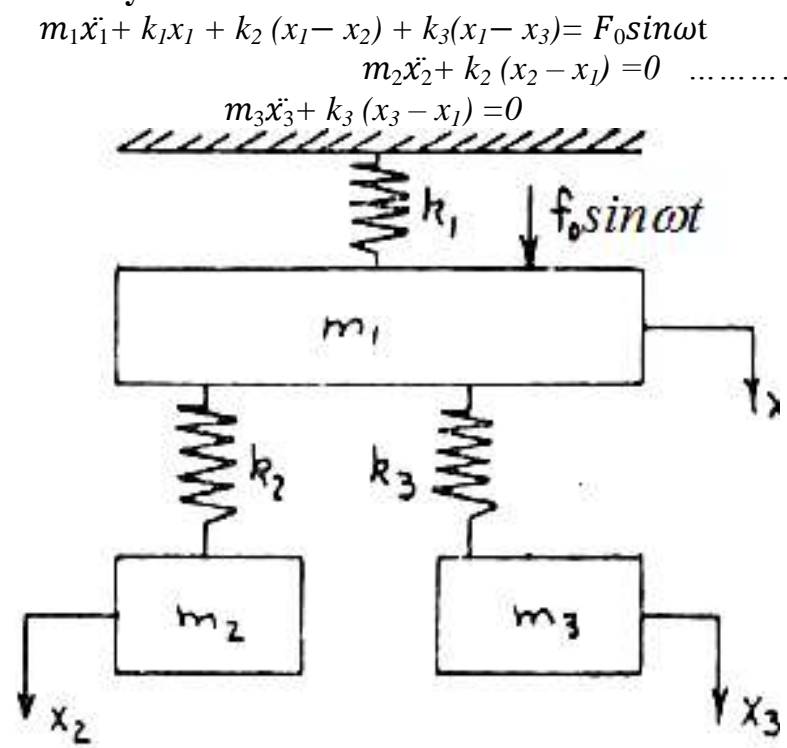

Figure III-5 Dual mass parallel vibration absorber

By assuming harmonic solution,

$X_{j}(t)=X_{j} \sin \omega \mathrm{t}, \quad j=1,2,3$

If $\mathrm{m}_{2}=m_{3}$ and $k_{2}=k_{3}$

Then 


$$
\begin{aligned}
& \frac{X_{1}}{X_{s t}}=\frac{\left[1-\frac{\omega^{2}}{\omega_{2}^{2}}\right]}{\frac{\omega^{4}}{\omega_{1}^{2} \omega_{2}^{2}}-\left[(1+\mu) \frac{\omega^{2}}{\omega_{1}^{2}}+\frac{\omega^{2}}{\omega_{2}^{2}}\right]+1} \\
& \frac{X_{2}}{X_{s t}}=\frac{1}{\frac{\omega^{4}}{\omega_{1}^{2} \omega_{2}^{2}}-\left[(1+\mu) \frac{\omega^{2}}{\omega_{1}^{2}}+\frac{\omega^{2}}{\omega_{2}^{2}}\right]+1}
\end{aligned}
$$

and $\mathrm{X}_{2}=\mathrm{X}_{3} ; \mu=\left(m_{2}+m_{3}\right) / m_{1}$

When $\omega_{2}=\omega ; \quad \mathrm{X}_{2}=\mathrm{X}_{3}=-\mathrm{F}_{0} / 2 \mathrm{~K}_{2}$

By this method we can minimize the amplitude of vibration of absorber mass as well as we increase the range of the mass ratio $(\mu)$. Dual mass DVA can't eliminate completely to frahm's conventional DVA but somewhat it is more advantages one.

\section{d. J.P. Den Hartog's damped dynamic Vibration Absorbers:}

The dynamic vibration absorber described

in the
previous

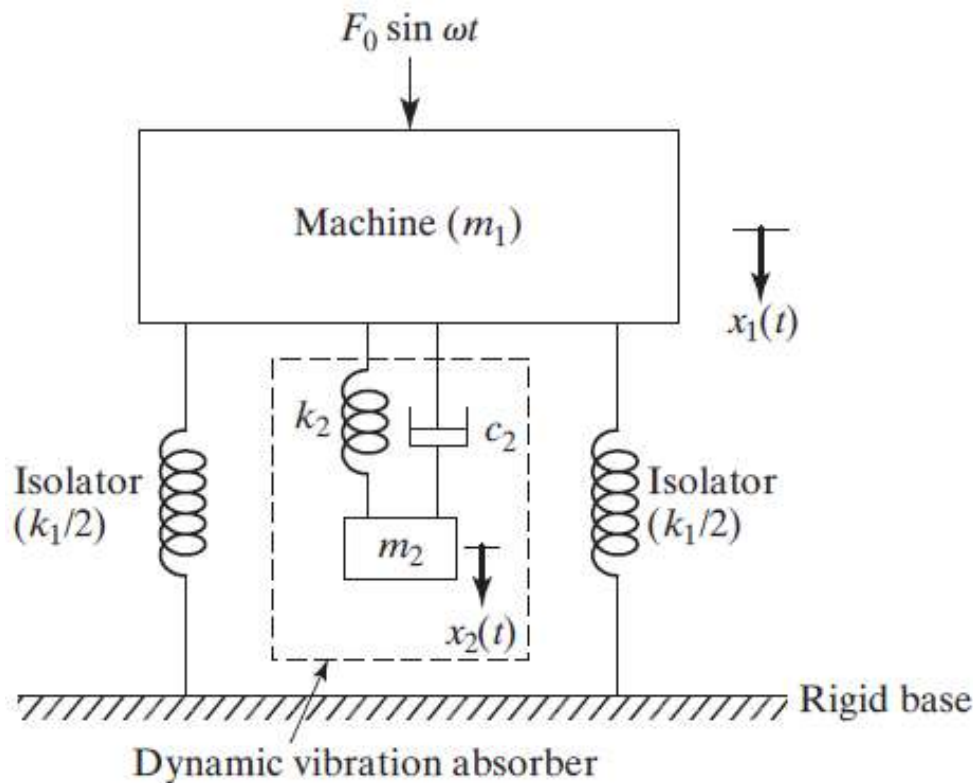

Figure III-6 Damped dynamic vibration absorber model A

The equations of motion of the masses $\mathrm{m}_{1}$ and $\mathrm{m}_{2}$ are

$$
\begin{aligned}
m_{1} \ddot{x_{1}}+k_{1} x_{1}+k_{2}\left(x_{1}-x_{2}\right)+C_{2}\left(\dot{x_{1}}-\dot{x_{2}}\right) & =F_{0} \sin \omega \mathrm{t} \\
m_{2} \ddot{x_{2}}+k_{2}\left(x_{2}-x_{1}\right) & +C_{2}\left(\dot{x_{2}}-\dot{x_{1}}\right)=0
\end{aligned}
$$

By assuming the solution to be

$X_{j}(t)=X_{j} e^{i \omega t}, \quad j=1,2$

The steady state solution of above Eqs.can be obtained:

And

$$
\frac{X_{1}}{X_{s t}}=\left[\frac{(2 \zeta g)^{2}+\left(\mathrm{g}^{2}-\mathrm{f}^{2}\right)^{2}}{(2 \zeta \mathrm{g})^{2}\left(\mathrm{~g}^{2}-1+\mu \mathrm{g}^{2}\right)^{2}+\left\{\mu \mathrm{f}^{2} \mathrm{~g}^{2}-\left(\mathrm{g}^{2}-1\right)\left(\mathrm{g}^{2}-\mathrm{f}^{2}\right)\right\}^{2}}\right]^{1 / 2}
$$

$$
\frac{X_{2}}{X_{s t}}=\left[\frac{(2 \zeta g)^{2}+f^{4}}{(2 \zeta g)^{2}\left(g^{2}-1+\mu g^{2}\right)^{2}+\left\{\mu f^{2} g^{2}-\left(g^{2}-1\right)\left(g^{2}-f^{2}\right)\right\}^{2}}\right]^{1 / 2}
$$

Eq. (15) shows that the amplitude of vibration of the main mass is a function of $\mathrm{g}$ and $\zeta$.The graph

of $\left(\frac{X_{1}}{X_{s t}}\right)$ against the forced frequency ratio $g=\omega / \omega_{\mathrm{n}}$ is shown in Fig.3-7 for $f=1$ and $\mu=1 / 20$ for a few different values of $\zeta$.

If damping $\left(c_{2}=\zeta=0\right)$ is zero then resonance occurs at the two undamped resonant frequencies of the 
system, a result that is already indicated in Fig.3-7. When the damping becomes infinite

$(\zeta=\infty)$ the two masses $m_{1}$ and $m_{2}$ are virtually clamped together, and the system behaves essentially

$$
\mathrm{g}=\frac{\omega}{\omega_{n}}=\frac{1}{\sqrt{1+\mu}}=0.9759
$$

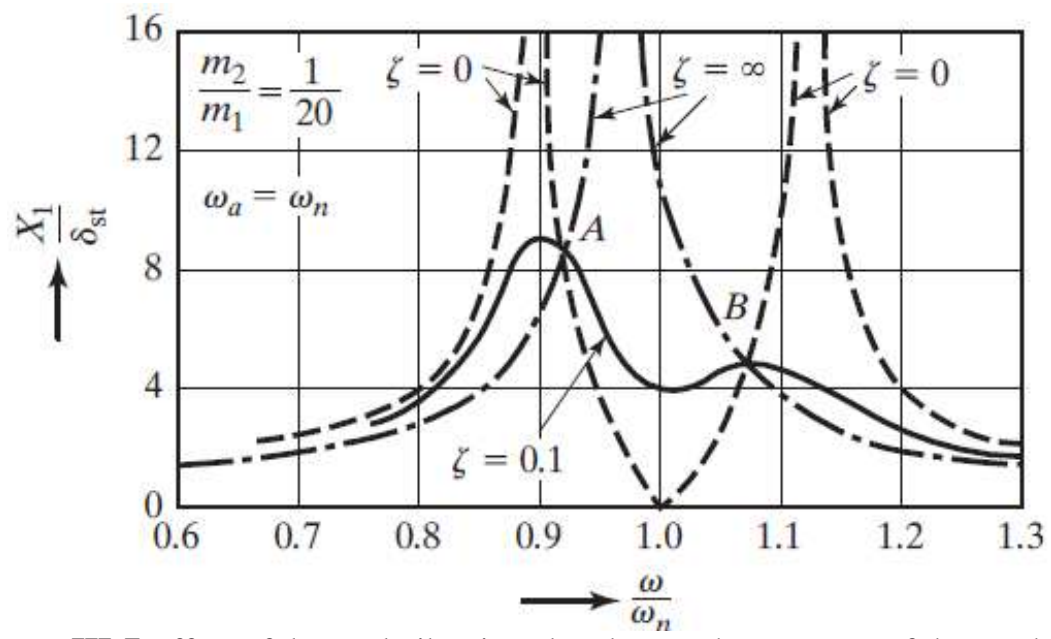

Figure III-7 Effect of damped vibration absorber on the response of the machine

Thus the peak of $X_{1}$ is infinite for $c_{2}$ as well as for $\mathrm{c}_{2}=\infty$. Somewhere in between these limits, the peak of $X_{1}$ will be a minimum.

\section{i. Optimally Tuned Vibration Absorber for}

\section{model A.}

It can be seen from Fig.III-8 that all the curves intersect at points $A$ and $B$ regardless of the value of

This is independent of $\zeta$ if $\frac{A}{C}= \pm \frac{B}{D}$.

$$
\frac{X_{1}}{X_{s t}}=\sqrt{\frac{A \zeta^{2}+B}{C \zeta^{2}+D}}
$$

damping. These points can be located by substituting the extreme cases of $\zeta=0$ and $\zeta=\infty$ into Eq. (15) and equating the two. This yields the following things. To see if there is any value of "g" for which $\left(\frac{X_{1}}{X_{s t}}\right)$ becomes independent of $\zeta$.The formula is the form

$$
\left(\frac{1}{g^{2}-1+\mu g^{2}}\right)^{2}=\left(\frac{g^{2}-f^{2}}{\mu f^{2} g^{2}-\left(g^{2}-1\right)\left(g^{2}-f^{2}\right)}\right)^{2}
$$

There are two values of $\mathrm{g}$ for which the above Eq.(17) is applicable. By taking -ve sign of right- hand side of Eq. (17), we got $\mathrm{g}=0$.this is trival but true solution and the other solution becomes

$$
\mathrm{g}^{4}-2 \mathrm{~g}^{2}\left(\frac{1+\mathrm{f}^{2}+\mu \mathrm{f}^{2}}{2+\mu}\right)+\frac{2 \mathrm{f}^{2}}{2+\mu}=0
$$

The two roots of Eq. (18) indicate the values of the frequency ratio, $g_{A}=\omega_{\mathrm{A}} / \omega$ and $g_{B}=$ $\omega_{\mathrm{B}} / \omega$, corresponding to the points $\mathrm{A}$ and $\mathrm{B}$. The ordinates of A and B can be found by substituting the values of $g_{A}$ and $g_{B}$ respectively, into Eq. (11). It has

been observed from fig.(3-7) that the most efficient vibration absorber is one for which the ordinates of the points $\mathrm{A}$ and $\mathrm{B}$ are equal. This condition requires that

substituting the values of $g_{A}$ and $g_{B}$ in Eq. (19) we got

$$
\frac{X_{1}}{X_{s t}}=\left(\frac{1}{1-\mathrm{g}^{2}(1+\mu)}\right)
$$

$$
\left(\frac{1}{1-\mathrm{g}_{A}^{2}(1+\mu)}\right)=\left(\frac{1}{1-\mathrm{g}_{B}^{2}(1+\mu)}\right)
$$

By simple algebra method the Eq.(20) corrected and becomes

$$
\mathrm{g}_{A}^{2}+\mathrm{g}_{B}^{2}=\frac{2}{1+\mu} \text {. }
$$

In Eq.(18) the sum becomes

$$
\mathrm{g}_{A}^{2}+\mathrm{g}_{B}^{2}=\frac{2\left(1+\mathrm{f}^{2}+\mu \mathrm{f}^{2}\right)}{2+\mu}
$$


Equating Eq.(21) and (22), result becomes

$f=\frac{1}{1+\mu}$

An absorber satisfying Eq. (23) can be correctly called the tuned vibration absorber. Although Eq. (23) indicates how to tune an absorber, it does not indicate the optimal value of the damping ratio $\zeta$ and the corresponding value of $\frac{X_{1}}{X_{s t}}$. The optimal value of $\zeta$ can be found by making the response curve as flat as possible at peaks $A$ and $B$. This can be achieved by making the curve horizontal at either $A$ or $B$, as shown in Fig. 3-8. For this, first Eq. (23) is substituted into Eq.(15) to make the resulting equation applicable to the case of optimum tuning. Then the modified Eq.(15) is differentiated with respect to $g$ to find the slope of $\frac{X_{1}}{X_{s t}}$. The curve of By setting the slope equal to zero at points $A$ and $B$, we obtain

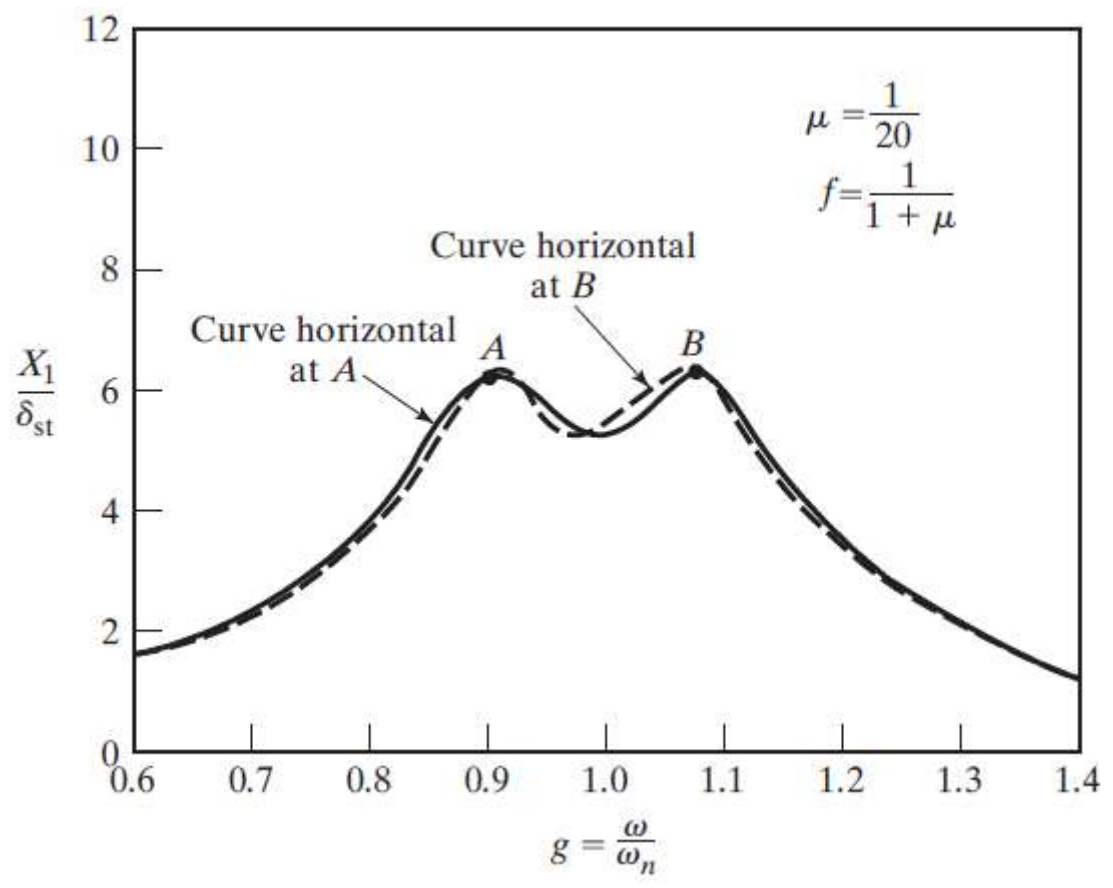

Figure III-9 Tuned vibration absorber

And

$$
\zeta^{2}=\frac{\mu\left\{3-\sqrt{\frac{\mu}{\mu+2}}\right\}}{8(1+\mu)^{3}} \quad \text { for point } A
$$

$$
\zeta^{2}=\frac{\mu\left\{3+\sqrt{\frac{\mu}{\mu+2}}\right\}}{8(1+\mu)^{3}} \quad \text { for point } B
$$

A convenient average value of $\zeta^{2}$ given by Eqs. (24) and (25) is used in design so that

$$
\zeta_{\text {optimal }}^{2}=\frac{3 \mu}{8(1+\mu)^{3}}
$$

The corresponding optimal value of $\frac{X_{1}}{X_{s t}}$ obtains by putting the value $\mathrm{g}$ from Eq.(18) in Eq.(19) becomes

$$
\left(\frac{X_{1}}{X_{\text {st }}}\right)_{\text {optimal }}=\left(\frac{X_{1}}{X_{s t}}\right)_{\max }=\sqrt{1+\frac{2}{\mu}}
$$

It can be seen from Eq. (16) that the amplitude of the absorber mass $\left(\mathrm{X}_{2}\right)$ is always much greater than that of the main mass $\left(\mathrm{X}_{1}\right)$ Thus the design should be able to

- Accommodate the large amplitudes of the absorber mass.
- $\quad$ Since the amplitudes of $\left(\mathrm{M}_{2}\right)$ are expected to be large, the absorber spring $\left(\mathrm{K}_{2}\right)$ needs to be designed from a fatigue point of view.

According to S.G.Kelly on his book "Fundamentals of Mechanical Vibrations", If the damping ratio is defined 
as $\zeta={ }^{C_{2}} / 2 m_{2} \omega_{a}$

Then $\zeta_{\text {opt }}=\sqrt{\frac{3 \mu}{8(1+\mu)}}$

Subsequently, Brock took a different approach which is quite clever, yet straight forward. No differentiation was needed. Based on the results, he

constant tuning. The constant tuning is defined as the case when $f=1$ can be given by

suggested that the optimum damping ratio for

$\zeta_{\text {opt }}=\sqrt{\frac{\mu(3+\mu)[1+\sqrt{\mu /(2+\mu)}]}{8(1+\mu)}}$

\section{e. Optimum parameters of model B:}

$$
\begin{aligned}
& \frac{X_{1}}{X_{S t}}=\left[\frac{(2 \zeta \mathrm{g})^{2}+\left(\mathrm{g}^{2}-\mathrm{f}^{2}\right)^{2}}{\left(1+\mu \mathrm{f}^{2}-\mathrm{g}^{2}\right)^{2}(2 \zeta \mathrm{g})^{2}+\left[\left(1-\mathrm{g}^{2}\right)\left(\mathrm{f}^{2}-\mathrm{g}^{2}\right)-\mu \mathrm{f}^{2} \mathrm{~g}^{2}\right]^{2}}\right]^{1 / 2} \\
& \frac{X_{2}}{X_{S t}}=\left[\frac{(2 \zeta \mathrm{g})^{2}+\mathrm{f}^{4}}{\left(1+\mu \mathrm{f}^{2}-\mathrm{g}^{2}\right)^{2}(2 \zeta \mathrm{g})^{2}+\left[\left(1-\mathrm{g}^{2}\right)\left(\mathrm{f}^{2}-\mathrm{g}^{2}\right)-\mu \mathrm{f}^{2} \mathrm{~g}^{2}\right]^{2}}\right]^{1 / 2} .
\end{aligned}
$$

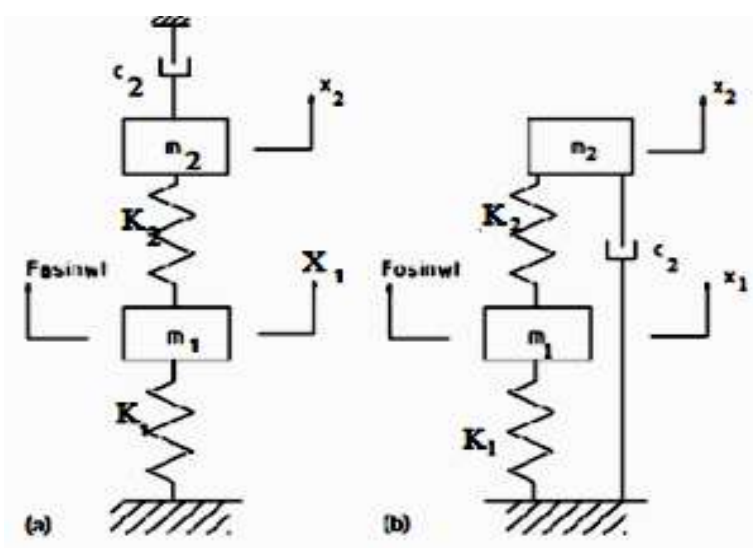

Figure III-10 Dynamic vibration absorber model B(a)skyhook damper(b)groundhook damper

Kefu Liu and Jie Liu, "The damped dynamic vibration absorbers: revisited and new result", has been provided the optimum parameter on model B.

$$
\begin{aligned}
f & =\frac{1}{\sqrt{1-\mu}} \\
\left(\frac{X_{1}}{X_{\text {st }}}\right)_{\text {optimal }} & =\left(\frac{X_{1}}{X_{\text {st }}}\right)_{\max }=\frac{2(1-\mu)}{\sqrt{2 \mu}} \\
\zeta_{\text {opt }} & =\frac{1}{2} \sqrt{\frac{3 \mu}{(1-\mu)(2-\mu)}}
\end{aligned}
$$

Brock also found the result for constant tuning. In the case of model $\mathrm{B}$, the ordinate of point $\mathrm{B}$ is greater than that of point $\mathrm{A}$ : We found that the optimum damping ratio is of the form:

$$
\zeta_{\text {opt }}=\frac{\sqrt{\mu[\mu+6-\sqrt{\mu(\mu+2)}]}}{4}
$$

Brock employed a perturbation method instead of differentiating a high-order equation. For model B to be optimum, a larger damping ratio is required. Overall, model B gives better vibration suppression. 


\section{f. Optimum parameters of model C:}

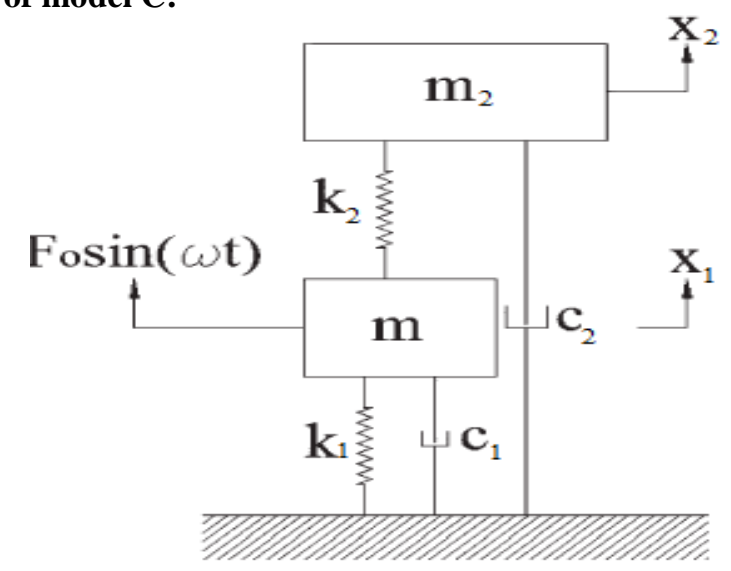

Figure III-11 Dynamic vibration absorber model C

The equation of motion for Model $\mathrm{C}$ is given by:

$\left[\begin{array}{cc}m_{1} & 0 \\ 0 & m_{2}\end{array}\right]\left[\begin{array}{c}\ddot{x}_{1} \\ \ddot{x_{2}}\end{array}\right]+\left[\begin{array}{cc}c_{1} & 0 \\ 0 & c_{2}\end{array}\right]\left[\begin{array}{l}\dot{x}_{1} \\ \dot{x_{2}}\end{array}\right]+\left[\begin{array}{cc}k_{1}+k_{2} & -k_{2} \\ -k_{2} & k_{2}\end{array}\right]\left[\begin{array}{l}x_{1} \\ x_{2}\end{array}\right]=\left[\begin{array}{c}F_{0} \\ 0\end{array}\right] \sin (\omega t)$

After solving the above equation of motion of model $\mathrm{C}$.

The normalized amplitude of the steady-state response of the primary mass is given as:

$$
\begin{aligned}
& \left(\frac{X_{1}}{X_{\text {st }}}\right)_{\text {optimal }}=\sqrt{\frac{\left(1-\frac{\mathrm{g}^{2}}{\mathrm{f}^{2}}\right)^{2}+4\left(\zeta_{a} \frac{\mathrm{g}}{\mathrm{f}}\right)^{2}}{\left(\frac{\mathrm{g}^{4}}{\mathrm{f}^{2}}-\left(\frac{4 \zeta a \zeta p}{\mathrm{f}}+\frac{1}{\mathrm{f}^{2}}+(\mu+1)\right) \mathrm{g}^{2}+1\right)^{2}+4\left(\mathrm{~g}\left(\zeta_{p}+\frac{\zeta a}{\mathrm{f}}\right)-\frac{\mathrm{g}^{3}}{\mathrm{f}}\left(\zeta a+\frac{\zeta p}{\mathrm{f}}\right)+\mathrm{gf} \zeta a \mu\right)^{2}}} . \\
& \left(\frac{X_{2}}{X_{\text {st }}}\right)_{\text {optimal }}=\sqrt{\frac{1+4\left(\zeta \frac{\mathrm{g}}{\mathrm{f}}\right)^{2}}{\left(\frac{\mathrm{g}^{4}}{\mathrm{f}^{2}}-\left(\frac{4 \zeta a \zeta p}{\mathrm{f}}+\frac{1}{\mathrm{f}^{2}}+(\mu+1)\right) \mathrm{g}^{2}+1\right)^{2}+4\left(\mathrm{~g}\left(\zeta_{p}+\frac{\zeta a}{\mathrm{f}}\right)-\frac{\mathrm{g}^{3}}{\mathrm{f}}\left(\zeta_{a}+\frac{\zeta p}{\mathrm{f}}\right)+\mathrm{gf} \zeta_{a} \mu\right)^{2}}} .
\end{aligned}
$$

Where

$$
\zeta_{p}=\frac{C_{1}}{2 m_{1} \omega_{p}}, \quad \zeta_{a}=\frac{C_{2}}{2 m_{2} \omega_{a}}
$$

Kefu Liu and Gianmarc Coppolahas been provided the optimum parameter on model C.

$$
f=\sqrt{\frac{1-4 \zeta_{p}^{2}}{1-\mu}}, \zeta_{a(\text { optimal })}^{*}=\frac{1}{2} \sqrt{\frac{3 \mu}{2-\mu}}
$$

It has been found that with an increase of the damping ratio $\zeta_{\mathrm{p}}$ or the mass ratio $\mu$, the optimum tuning parameter $f$ decreases and the optimum damping ratio $\zeta_{\mathrm{a}}$ increases.

\section{g. Optimum parameters of model D:}

Analysis of Parallel Damped Dynamic Vibration Absorbers:

The equations of motion can be readily written as:

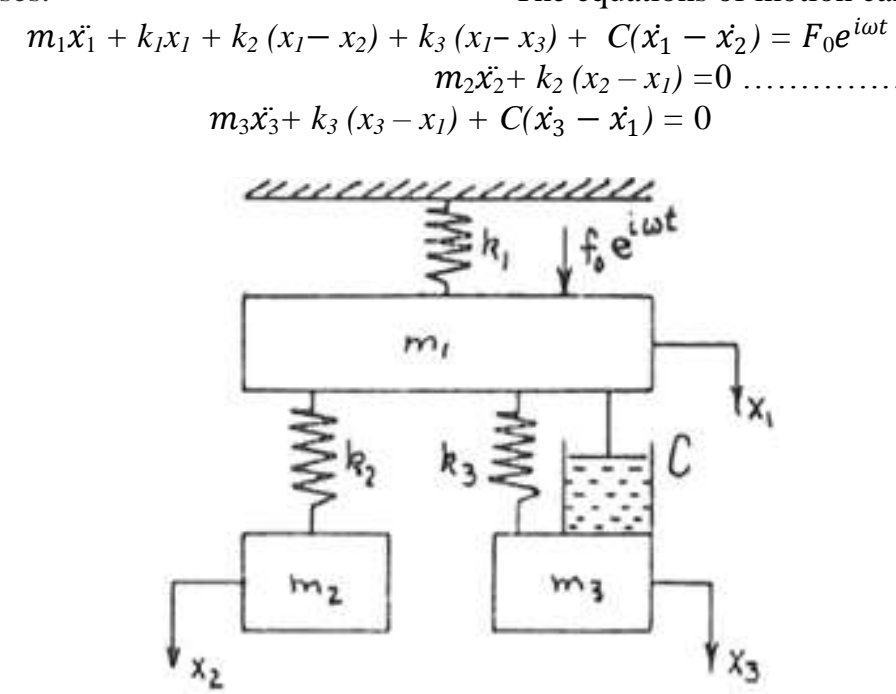


Figure III-12 parallel dual mass damped dynamic vibration absorber

$$
\begin{aligned}
& f=\omega_{3} / \omega_{1}, g=\omega / \omega_{1}, h=\omega_{2} / \omega_{1}, \mu_{2}=\mathrm{m}_{2} / \mathrm{m}_{1}, \mu_{3}=\mathrm{m}_{3} / \mathrm{m}_{1}, \zeta=\mathrm{C} / \mathrm{C}_{\mathrm{c}}=C / 2 m_{2} \omega_{p} \\
& \frac{X_{1}}{X_{s t}}=\frac{\left(1-\frac{g^{2}}{\mathrm{f}^{2}}-\frac{\mathrm{g}^{2}}{\mathrm{~h}^{2}}+\frac{\mathrm{g}^{4}}{\mathrm{f}^{2}}\right)+i 2 \zeta \frac{\mathrm{g}}{\mathrm{f}^{2}}\left(1-\frac{\mathrm{g}^{2}}{\mathrm{~h}^{2}}\right)}{\left[\begin{array}{l}
\left(1+\mu_{2} \mathrm{~h}^{2}+\mu_{3} \mathrm{f}^{2}-\mathrm{g}^{2}\right)\left(1-\frac{\mathrm{g}^{2}}{\mathrm{f}^{2}}-\mathrm{g}^{2}\right. \\
\left.\left.\left.\mathrm{h}^{2}+\frac{\mathrm{g}^{4}}{\mathrm{f}^{2} \mathrm{~h}^{2}}\right)+\mu_{2} \mathrm{~h}^{2}\left(\frac{\mathrm{g}^{2}}{\mathrm{f}^{2}}-1\right)+\mu_{3} \mathrm{f}^{2}\left(\frac{\mathrm{g}^{2}}{\mathrm{~h}^{2}}-1\right)\right\}\right] \\
+i 2 \zeta g \mu_{3}\left\{\left(1-\frac{g^{2}}{\mathrm{f}^{2}}-\frac{\mathrm{g}^{2}}{\mathrm{~h}^{2}}+\frac{\mathrm{g}^{4}}{\mathrm{f}^{2} \mathrm{~h}^{2}}\right)+\left(1-\frac{\mathrm{g}^{2}}{\mathrm{~h}^{2}}\right)\left(\frac{\mu_{2} \mathrm{~h}^{2}}{\mu_{3} \mathrm{f}^{2}}+\frac{11}{\mu_{3} \mathrm{f}^{2}}-\frac{1 \mathrm{~g}}{\mu_{3} \mathrm{f}^{2}}-1\right)-\frac{\mu_{2} \mathrm{~h}^{2}}{\mu_{3} \mathrm{f}^{2}}\right)
\end{array}\right]} \\
& D \frac{X_{2}}{X_{s t}}=\left(1-\frac{\mathrm{g}^{2}}{\mathrm{f}^{2}}\right)+i 2 \zeta \frac{\mathrm{g}}{\mathrm{f}^{2}} \\
& D \frac{X_{3}}{X_{s t}}=\left(1-\frac{\mathrm{g}^{2}}{\mathrm{~h}^{2}}\right)\left\{1+i 2 \zeta \frac{\mathrm{g}}{\mathrm{f}^{2}}\right\}
\end{aligned}
$$

It can be easily shown that $\frac{X_{1}}{X_{s t}}$ is independent of the damping ratio provided if

$$
\frac{A}{C}= \pm \frac{B}{D}
$$

Omitting the minor details of calculation, the above equation may be shown to reduce to (when the minus sign is chosen):

This is a trivial, but true, equation. According to Eq.(33), the vibratory displacement of the main mass $X_{I}$ is independent of damping when $g=0$, i.e., when the forcing frequency is zero or when $h=g$, i.e., when the forcing frequency is the same as the natural frequency of the undamped absorber mass.

$$
\left\{g^{4}(2+\mu)-2 g^{2}\left(2 \mu f^{2}+f^{2}+1\right)+2 f^{2}\right\}\left(g^{2}-f^{2}\right)=0 .
$$

Since $g=f$ corresponds to the null, the dimensionless frequencies $g$ at which the amplitudes $\frac{X_{1}}{X_{s t}}$ are independent of damping are given by

$$
g^{4}-\frac{2 g^{2}\left(2 \mu f^{2}+f^{2}+1\right)}{(2+\mu)}+\frac{2 f^{2}}{(2+\mu)}=0
$$

Eq. (38) is a quadratic in $\mathrm{g}^{2}$ and provides the two required values of $g$ (say $g_{1}$ and $g_{2}$ ). Using the values of $g_{l}$ and $g_{2}$, the corresponding values of the ratio $\frac{X_{1}}{X_{s t}}$ may be computed from a simplified equation obtained from Eq. (33) i.e.,

$$
\left(\frac{X_{1}}{X_{s t}}\right)_{\mathrm{g}_{1}, \mathrm{~g}_{2}}=\frac{f^{2}-\mathrm{g}^{2}}{\mathrm{~g}^{4}-\mathrm{g}^{2}\left(2 \mu f^{2}+f^{2}+1\right)+f^{2}}
$$

The amplitudes at $g_{1}$ and $g_{2}$ as computed from Eq. (39) are in general but not equal. By doing some mathematical calculation, we got

$$
f^{2}=\frac{1-\mu}{(1+2 \mu)^{2}} .
$$

The required tuning, the so-called favorable tuning, which gives equal amplitudes can be calculated from Eq. (40). 36.6 percent of the main mass is required for the absorber mass in order to attain a maximum bandwidth of $\left(g_{1}-g_{2}\right)$.

However, such a mass ratio is too high and prohibitive to tie of any practical use.The parallel absorber appears to be superior to the conventional clamped absorber if a comparison is made between the response curves for a damping ratio such as $\zeta=$ 0.32

\section{SYSTEM DESIGN}

\section{a. Primary System Design:}

- Simply supported Beam

- $\quad$ Material $=$ Mild steel

- $\operatorname{Density}(\rho)=7850 \mathrm{~kg} / \mathrm{m}^{3}$

- Mass per unit length $(\mathrm{m})=3.84 \mathrm{~kg} / \mathrm{m}$

- $\quad$ Length $(1)=0.415$ meters

- $\operatorname{Breadth}(b)=0.05$ meters 
- $\operatorname{Height}(\mathrm{d})=0.0098$ meters

- $\quad$ Mass $=1.5963 \mathrm{~kg}$

- $\quad$ Natural Frequency $\left(\omega_{\mathrm{n}}\right)=(\beta l)^{2} \sqrt{\frac{E I}{\rho A l^{4}}}$

Table4.2 First four natural frequency for different modes of vibrating simply supported beam.

\begin{tabular}{|l|l|l|}
\hline Mode & $\begin{array}{l}\text { Theoretical frequency }\left(\omega_{\mathrm{n}}\right) \text { in } \\
(\mathrm{rad} / \mathrm{sec})\end{array}$ & $\begin{array}{l}\text { FE analysis frequency } \\
\text { in }(\mathrm{rad} / \mathrm{sec})\end{array}$ \\
\hline 1 & 818.35 & $132.63 \times 2 \pi=833.33$ \\
\hline 2 & 3273.4 & $527.15 \times 2 \pi=3312.18$ \\
\hline 3 & 7365.15 & $1170.1 \times 2 \pi=7352$ \\
\hline 4 & 13903.6 & $1995.2 \times 2 \pi=12536.211$ \\
\hline
\end{tabular}

Amplitude and mode shape of simply supported corresponding $\left(\omega_{\mathrm{n}}\right)$. The steps have been followed for beam can be calculated by using ansys software at its the solutions are given in Fig 4-1.

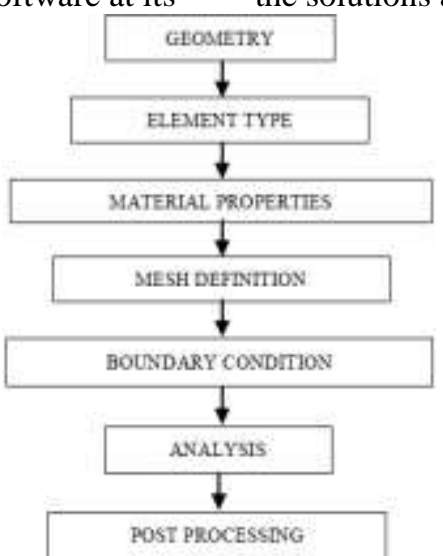

Figure IV-1 Solution steps in ANSYS

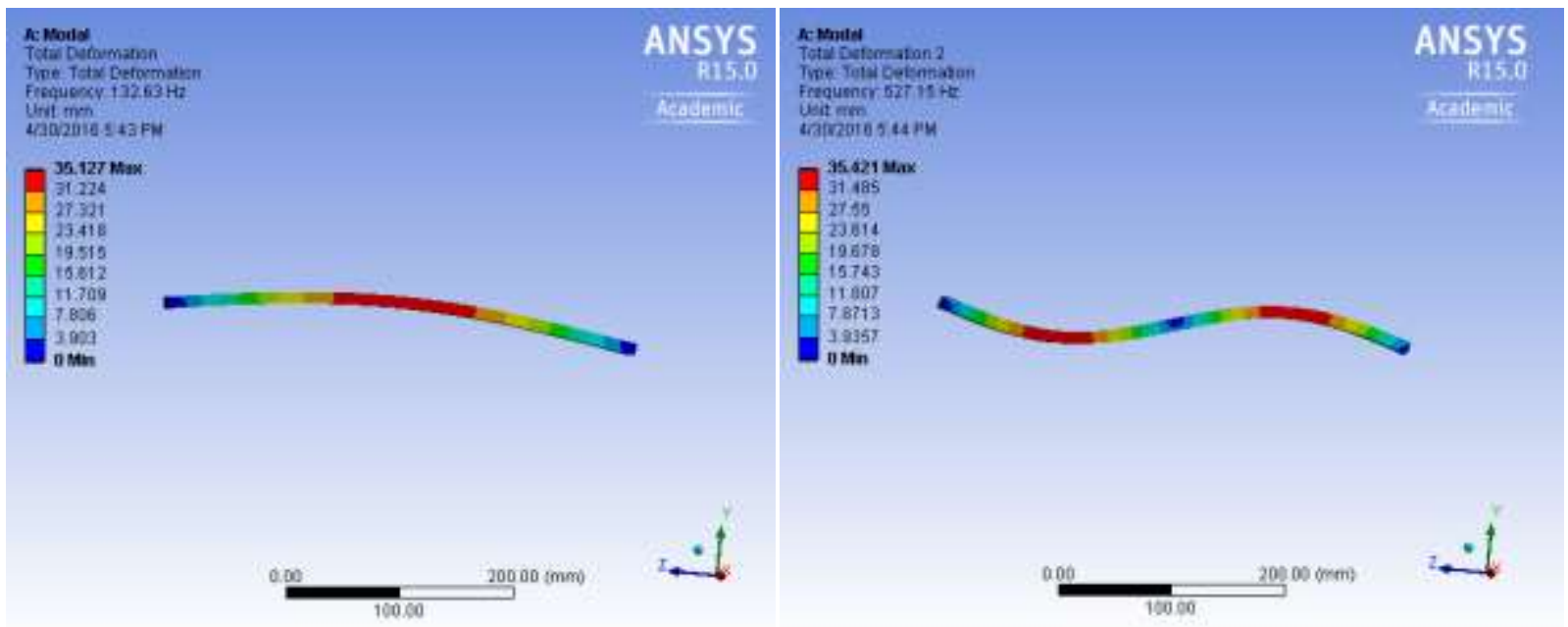



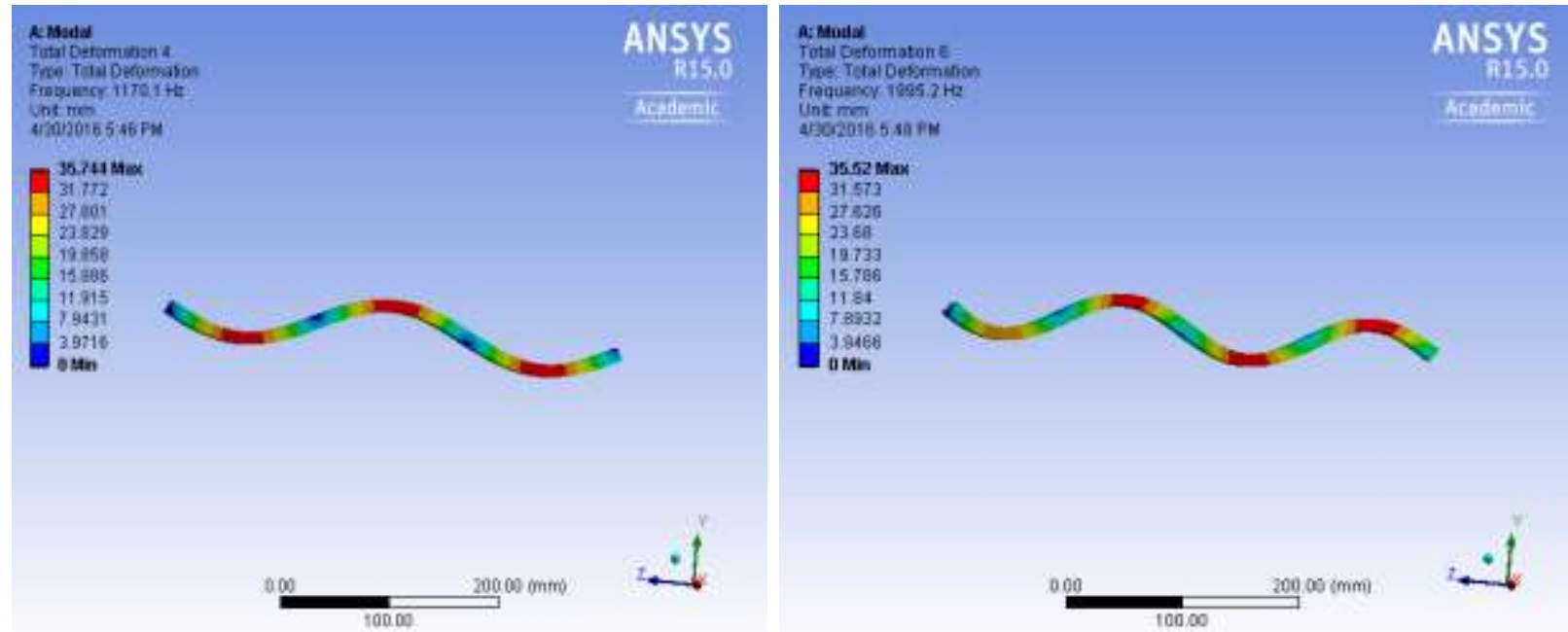

Figure IV-2 First 4 Natural Frequencies for different modes of vibration for simply supported beam

It is seen that those values are obtained from theoretically and obtained from FE analysis are given in table No.1 and they are somewhat deviate from each other but nearly equal.

\section{b. Design of dual mass dynamic vibration absorber:}

The dynamic vibration absorbers are designed for Simply supported beam type main vibrating system, when main systems are excited at its fundamental naturalfrequency. An absorber mass of $25 \%$ of the mass of main system [i.e. $\mu=0.25$ ] is taken for design. Absorber consist of a cantilever beam type arm having Specifications Are As Follows:

For $\operatorname{rod} \phi=5 \mathrm{~mm}$

Length $=70 \mathrm{~mm}$

Material $=$ mild steel(MS), E=200Gpa,$\rho=7850$ $\mathrm{kg} / \mathrm{m}^{3}$

M. I .of the beam $\mathrm{I}=\pi \mathrm{d}^{4} / 64=3.068 \times 10^{-11} \mathrm{~m}^{4}$

But as absorber arm is made up of 2 rods of $70 \mathrm{~mm}$.

MI of the arm, $\mathrm{I}=2 \mathrm{I}_{1}=3.068 \times 10^{-11} \times 2=6.135923$

$\mathrm{x} 10^{-11} \mathrm{~m}^{4}$

From mathematical model of absorber system,

Mass of absorbers $=\mathrm{m}_{\mathrm{a}}+\mathrm{m}_{\mathrm{b}}=0.25 \mathrm{x}$ mass or the simply supported beam type main vibrating system $=0.25 \mathrm{x}$ $1.5963=0.3991 \mathrm{~kg}$. $\mathrm{m}_{\mathrm{a}}=\mathrm{m}_{\mathrm{b}}=0.1995 \mathrm{~kg}$.

At tunning condition $\omega_{\mathrm{n}}=\omega_{\mathrm{a}}$. $\omega_{\mathrm{n}}{ }^{2}=\mathrm{k}_{2} / \mathrm{m}_{2}$

therefore ,

At fundamental natural frequency, designed $\mathrm{k}_{2}$ $=818.35^{2} \times 0.1995=133.604 \mathrm{KN} / \mathrm{m}$.

But secondary mass attached to primary system acts as a cantilever beam.therfore length of absorber system will be calculated using the formula, $\mathrm{k}_{1}=\mathrm{p} / \mathrm{y}$ $=3 \mathrm{EI} / 1_{1}^{3}$.

Therefore $l_{1}=65.073 \mathrm{~mm}$.

Analysis of parallel dual-mass DVA for a spring instead of a rod in secondary system design. By using the stiffness formula

$K=\frac{\left(r^{4} G\right)}{\left(4 R^{3} N\right)}$ where $\mathrm{r}=$ wire radius, $\mathrm{R}=$ coil radius,

$\mathrm{G}=$ modulus of rigidity

From the above formula we can findout the no. of turns $(\mathrm{N})$ of a spring by taking the value of $r, \mathrm{R}$ and $\mathrm{G}$ from the available spring in the market. The commonly used spring in the market are made up material like ASTM A228(high carbon spring) and ASTM A231(alloy steel). According to the load, we take proper material so that its deflection and stress can't be increased up to its desired limit.

Table 4.3 Typical properties of common spring materials:

\begin{tabular}{|c|c|c|c|c|c|}
\hline Material/Specication & $\begin{array}{l}\text { Elastic } \\
\text { modulus(E) in } \\
(\mathrm{GPa})\end{array}$ & $\begin{array}{l}\text { Shear } \\
\text { Modulus(G) in } \\
(\mathrm{GPa})\end{array}$ & $\begin{array}{l}\text { Density }(\rho \\
) \text { in } \\
\mathrm{Kg} / \mathrm{m}^{3}\end{array}$ & $\begin{array}{l}\text { Maximum service } \\
\text { Temperature }\left({ }^{\circ} \mathrm{C}\right)\end{array}$ & $\begin{array}{c}\text { Principal } \\
\text { characteristic }\end{array}$ \\
\hline $\begin{array}{l}\text { High-carbon steels } \\
\text { Music Wire ASTM A } \\
228 \\
\text { Hard Drawn ASTM A } \\
227\end{array}$ & $\begin{array}{l}207 \\
207\end{array}$ & $\begin{array}{l}79.3 \\
79.3\end{array}$ & $\begin{array}{l}7840 \\
7840\end{array}$ & $\begin{array}{l}120 \\
120\end{array}$ & $\begin{array}{l}\text { High strength; } \\
\text { excellent fatigue } \\
\text { life; general purpose } \\
\text { use; poor fatigue life }\end{array}$ \\
\hline $\begin{array}{l}\text { Stainless steels } \\
\text { Martensitic(AISI } \\
410,420 \text { ) } \\
\text { Austenitic(AISI }\end{array}$ & $\begin{array}{l}200 \\
193\end{array}$ & $\begin{array}{l}75.8 \\
68.9\end{array}$ & $\begin{array}{l}7750 \\
7840\end{array}$ & $\begin{array}{l}250 \\
315\end{array}$ & $\begin{array}{l}\text { Unsatisfactory for } \\
\text { sub-zero } \\
\text { application. } \\
\text { Good strength at }\end{array}$ \\
\hline
\end{tabular}




\begin{tabular}{|c|c|c|c|c|c|}
\hline 301,302$)$ & & & & & moderate. \\
\hline $\begin{array}{l}\text { Copper based alloys } \\
\text { Spring brass(ASTM } \\
\text { B134) } \\
\text { Phosphor } \\
\text { bronze(ASTM B159) } \\
\text { Beryllium copper } \\
\text { (ASTM B197) }\end{array}$ & $\begin{array}{l}110 \\
103 \\
131\end{array}$ & $\begin{array}{l}41.4 \\
43.4 \\
44.8\end{array}$ & $\begin{array}{l}8520 \\
8860 \\
8220\end{array}$ & $\begin{array}{l}90 \\
90 \\
200\end{array}$ & $\begin{array}{l}\text { Low cost; High } \\
\text { conductivity; Poor } \\
\text { Mechanical } \\
\text { properties . } \\
\text { Ability to withstand } \\
\text { repeated flexures } \\
\text { High yield and } \\
\text { Fatigue strength; } \\
\text { Hardenable }\end{array}$ \\
\hline $\begin{array}{l}\text { Nickel-based alloys } \\
\text { Inconel } 600 \\
\text { Inconel X-750 } \\
\text { Ni-span C }\end{array}$ & $\begin{array}{l}214 \\
214 \\
186\end{array}$ & $\begin{array}{l}75.8 \\
75.8 \\
66.2\end{array}$ & $\begin{array}{l}8500 \\
8250 \\
8140\end{array}$ & $\begin{array}{l}315 \\
600 \\
90\end{array}$ & $\begin{array}{l}\text { Good strength; High } \\
\text { corrosion resistance } \\
\text { Precipitation } \\
\text { hardening for high } \\
\text { temp } \\
\text { Constant modulus } \\
\text { over a wide } \\
\text { temperature range. }\end{array}$ \\
\hline
\end{tabular}

Shear stress of spring,

$\tau=K_{w} \frac{8 W D}{\pi d^{3}}$

The combined effect of direct shear and curvature correction is accounted by Wahl's correction factor $\left(\mathrm{K}_{\mathrm{w}}\right)$ and is given as: $K_{w}=\frac{4 c-1}{4 c-4}+\frac{0.615}{c} \quad(\mathrm{c}=\mathrm{d} / \mathrm{D})$.

Deflection of spring,

$\mathrm{X}=\frac{8 W D^{3} N}{G d^{4}}$.

\section{RESULTS AND DISCUSSIONS}

The responses of the main mass and the $\mathbf{b}$. absorber masses have been represented graphically as functions of the frequency ratio $g$ by using MATLAB. In order to judge the effectiveness of the parallel vibrationabsorber, the responses of the conventional absorber are compared with those of the corresponding parallel vibration absorber. a.

Optimisation of model A damped dynamic
vibration absorber:
Using MATLAB, we plot the variations of
vibration amplitudes of the main and auxiliary
masses of a vibration absorber model(A) of Eqs. (15)
and (16) as functions of the frequency ratio(g).




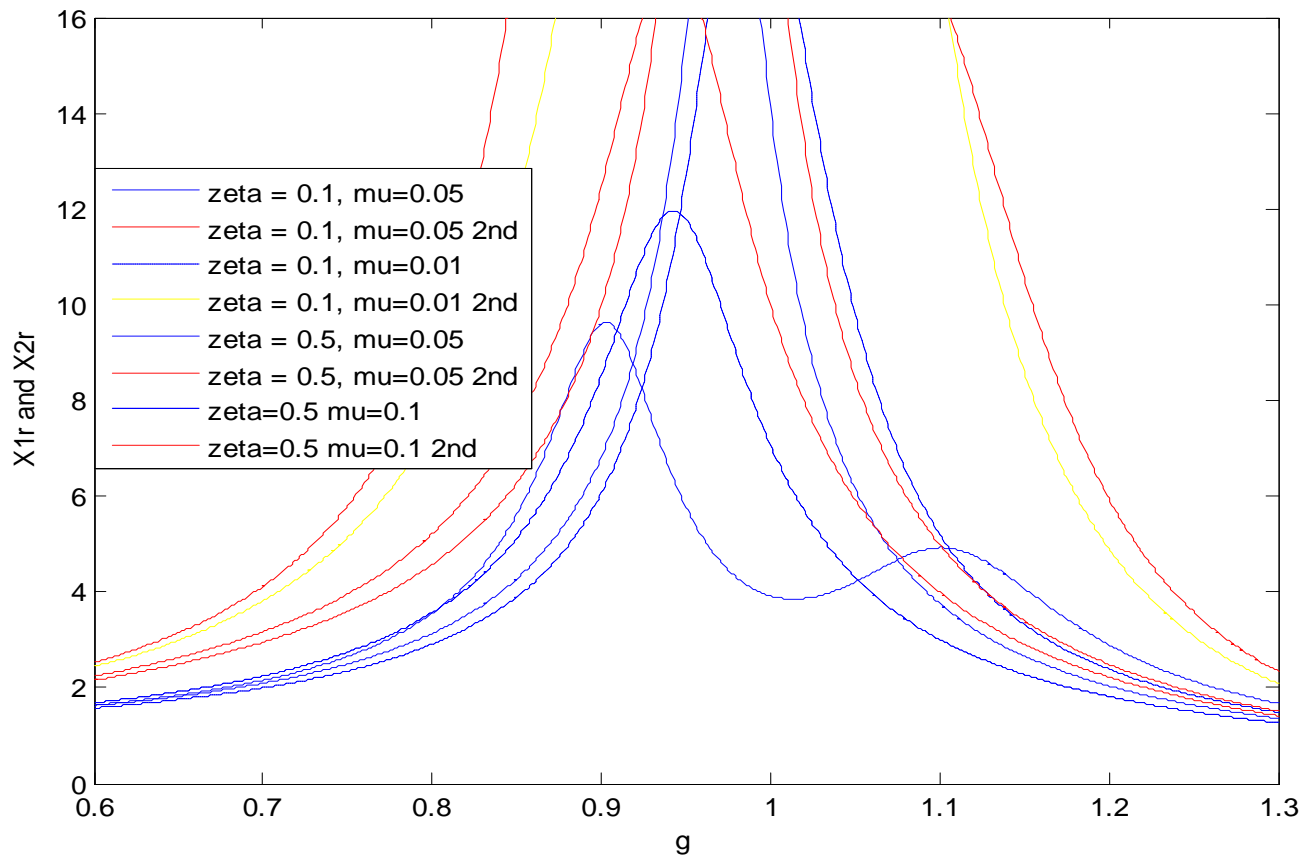

Figure V-1 Response of combined system at different mass ratio and damping ratio for model A
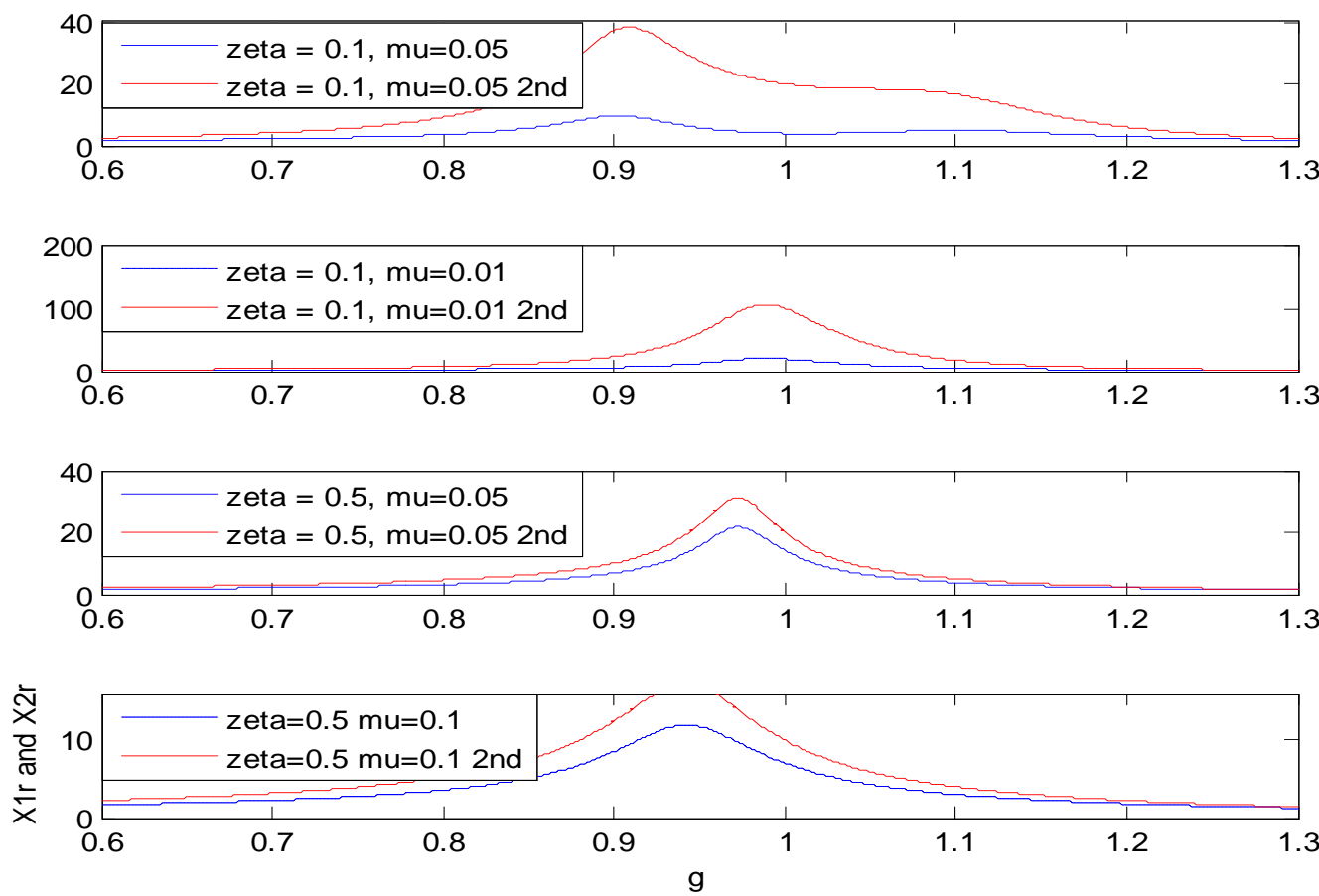

Figure V-2 Subplot response of combined system at different mass ratio and damping ratio for model A From the above curve, we see the non-linear $\mathbf{c}$. variation of amplitude of vibrating system. For model d. Optimisation of model B damped dynamic A, the ordinate of point $\mathrm{A}$ is greater than that of point $\mathrm{B}$ : The optimum damping ratio is considered to be the value for which the FRF curve passes horizontally through point $\mathrm{A}$ and it goings to optimize at $\zeta=0.27$ and $f=0.8$ for $\mu=0.25$.

Similarly the effect of mass ratio and also the effect of variation of the primary system damping factor of the remaining models are simulated as follows,

\section{vibration absorber:}

Using MATLAB, we plot the variations of vibration amplitudes of the main and auxiliary masses of a vibration absorber model(B) of Eq. (28) and (29) as functions of the frequency ratio(g). 


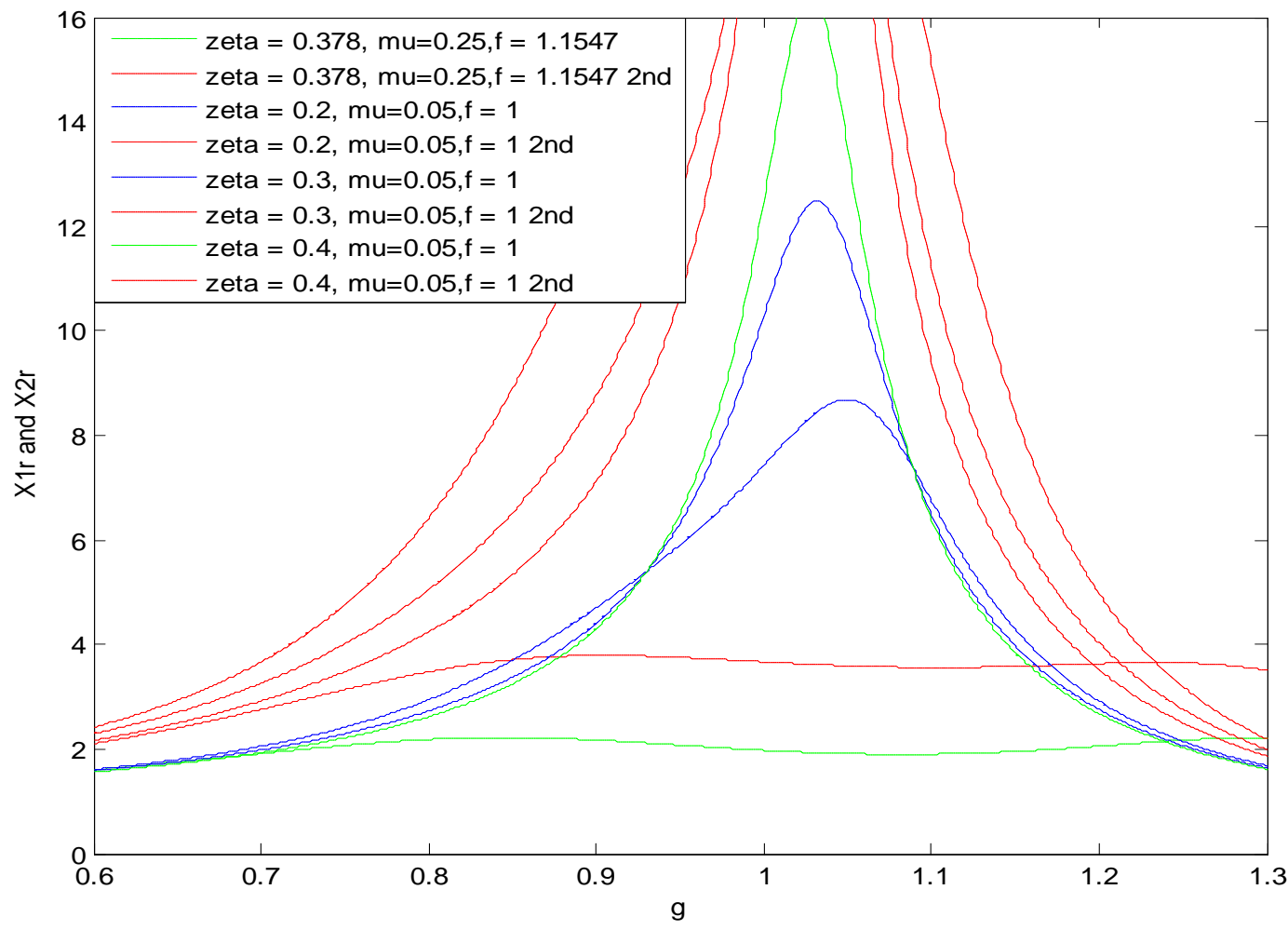

Figure V-3 Response of combined system at different mass ratio and damping ratio for model B compared with optimal

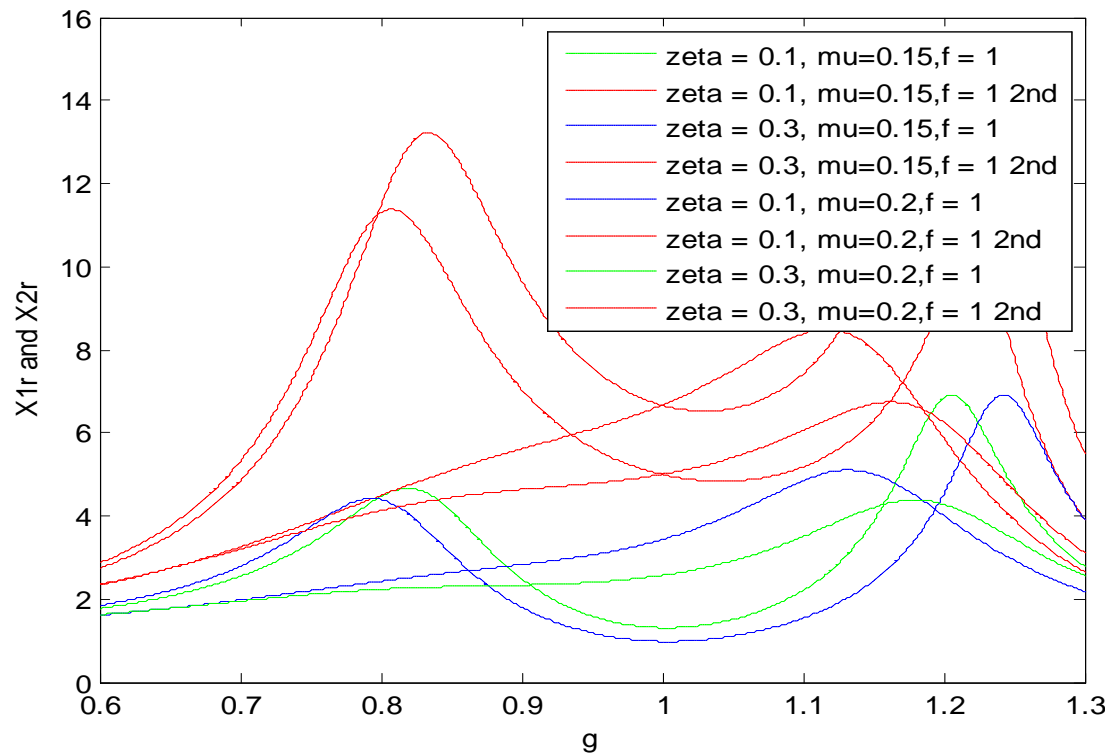

Figure V-4 Response of combined system at different mass ratio and damping ratiofor model B at const. tunning

From the above curve, we see the non-linear $\mathbf{e}$. variation of amplitude of vibrating system.For model $\mathrm{B}$, the ordinate of point $\mathrm{B}$ is greater than that of point A. The optimum damping ratio is considered to be the value for which the FRF curve passes horizontally through point Band it goings to optimize at $\zeta=0.378$ and $\mathrm{f}=1.1547$ for $\mu=0.25$.
Optimisation of model $C$ damped dynamic vibration absorber:

Using MATLAB, we plot the variations of vibration amplitudes of the main and auxiliary masses of a vibration absorber model(C) of Eqs. (30) and (31) as functions of the frequency ratio $(\mathrm{g})$. 


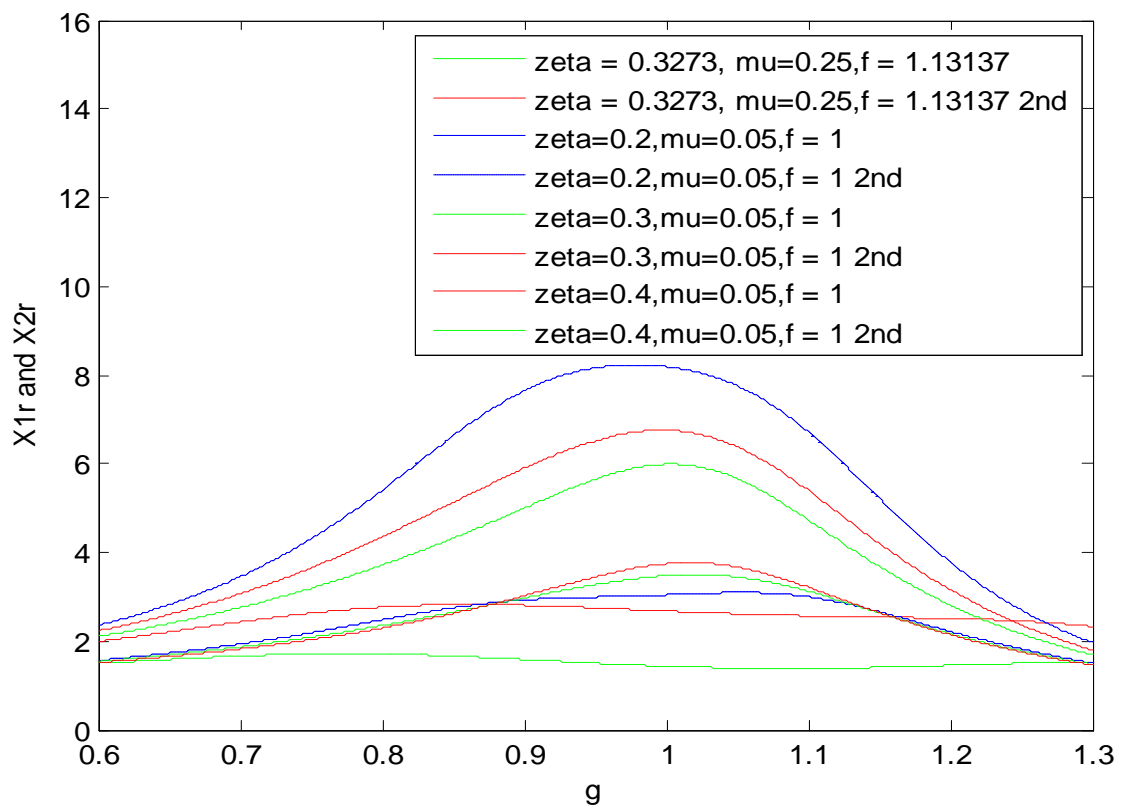

Figure V-5 Response of combined system at different mass ratio and damping ratiofor model C compared with optimal

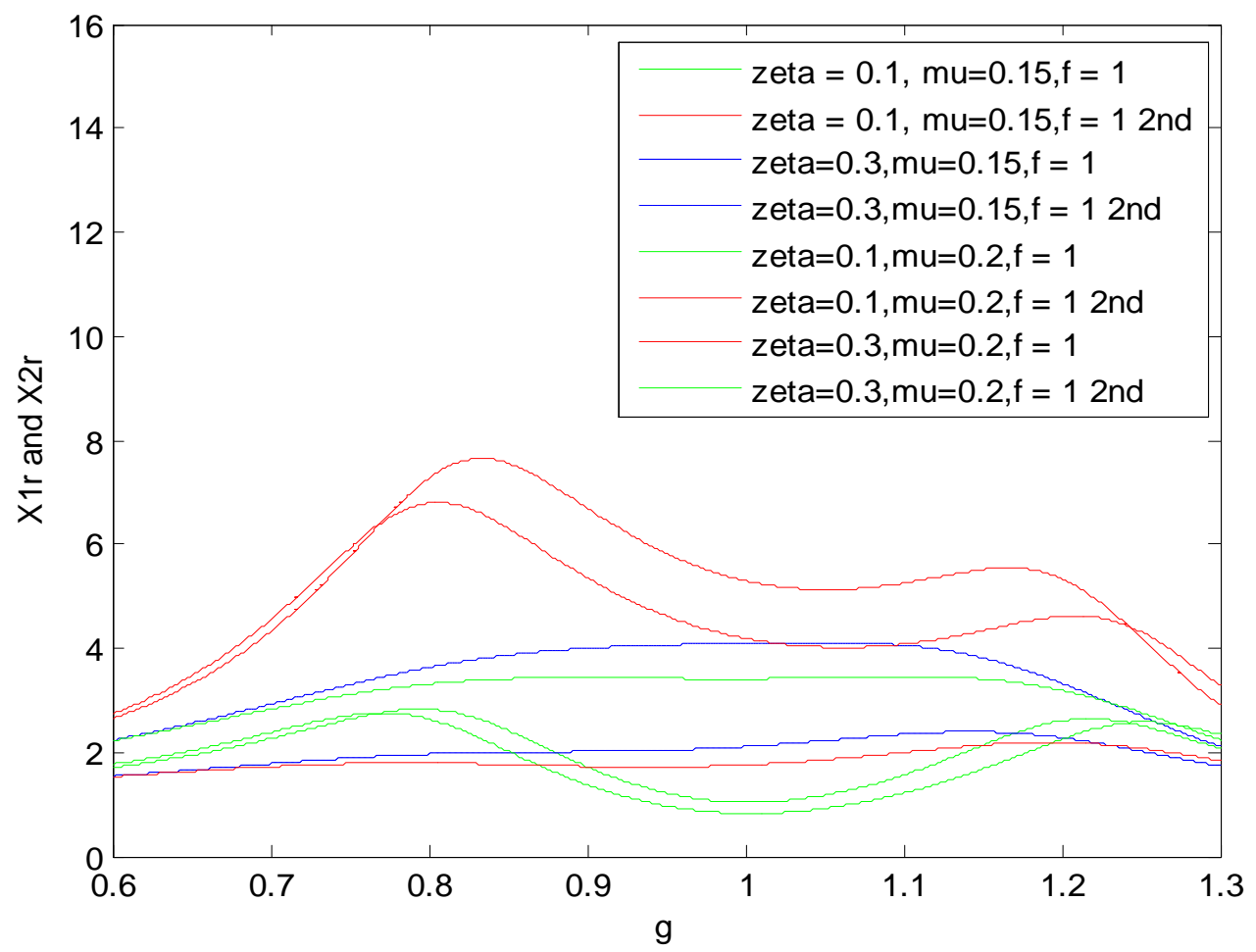

Figure V-6 Response of combined system at different mass ratio and damping ratio for model C at const. tunning

From the above curve, we see the non-linear $\mathbf{f}$. Optimisation of model $\mathbf{D}$ damped dynamic variation of amplitude of a vibrating system For model $\mathrm{C}$, the ordinate of point $\mathrm{A}$ is greater than that of point $\mathrm{B}$ : The optimum damping ratio is considered to be the value for which the FRF curve passes horizontally through point Aand it goings to optimize at $\zeta=0.3273$ and $\mathrm{f}=1.13137$ for $\mu=0.25$. vibration absorber:

Using MATLAB, we plot the variations of vibration amplitudes of the main and auxiliary masses for a vibration absorber model(D) of Eqs (33) and (34) as functions of the frequency $\operatorname{ratio}(\mathrm{g})$. 


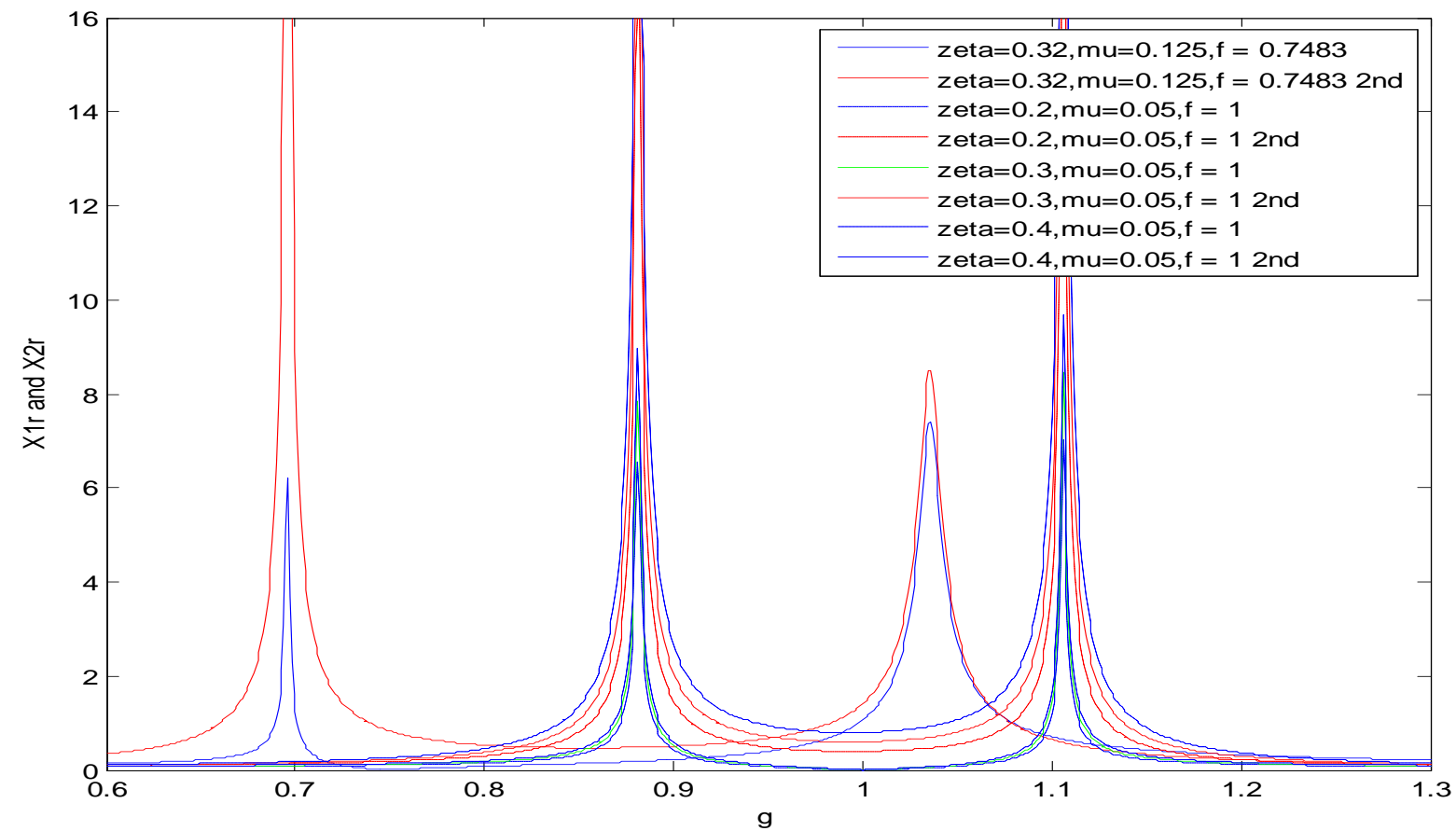

Figure V-7 Response of combined system at different mass ratio and damping ratio for model D compared with optimal
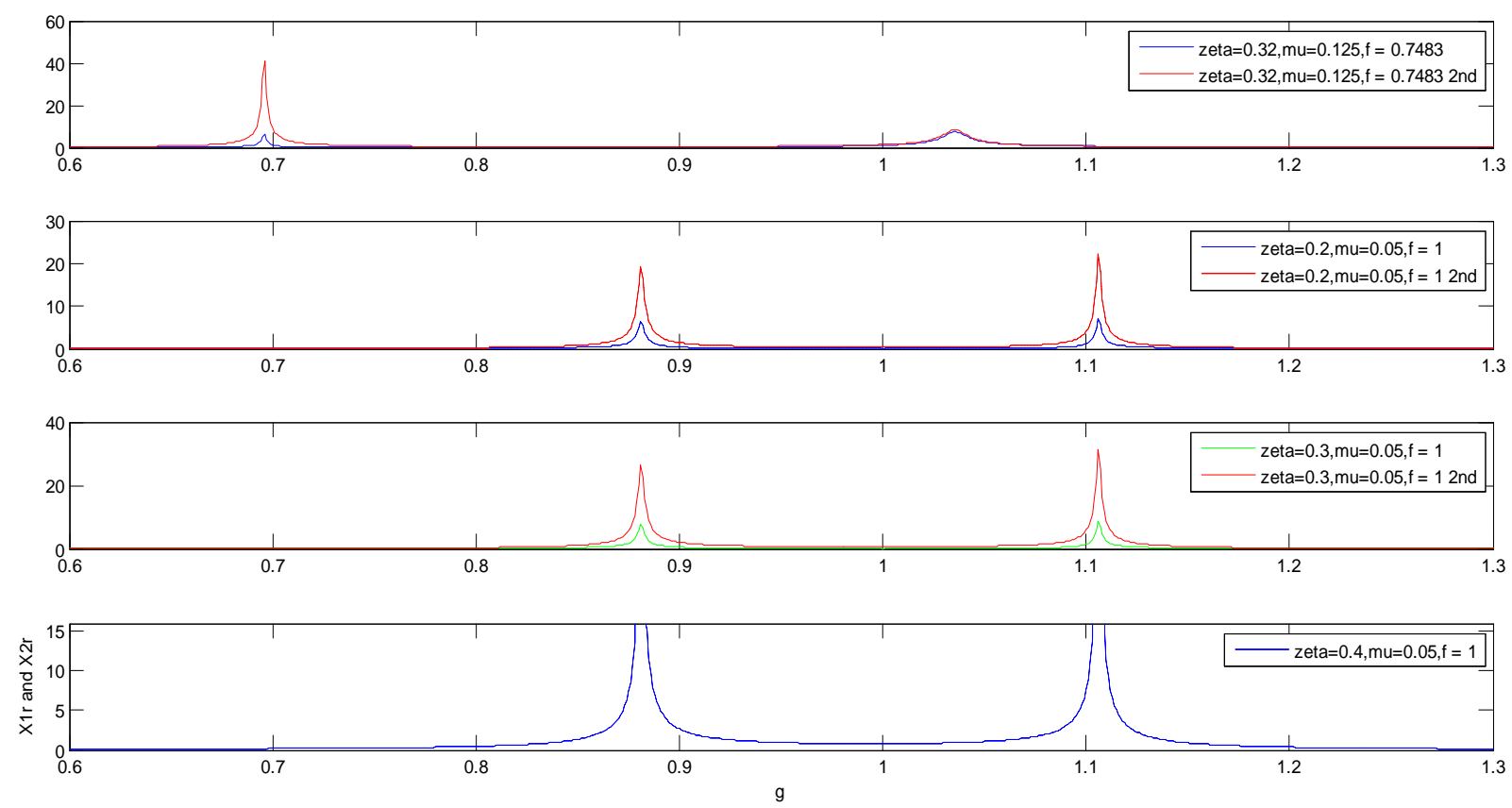

Figure V-8 Subplot response of combined system at different mass ratio and damping ratio for model D at const. tunning 


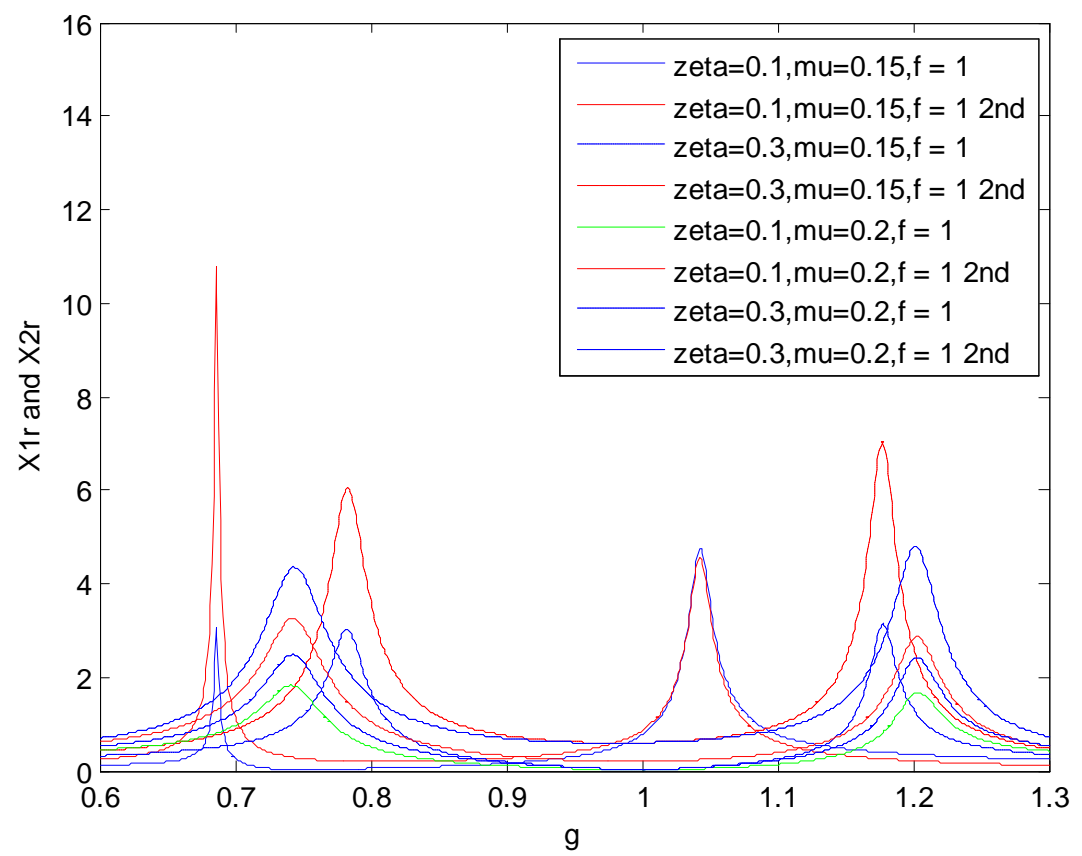

Figure V-9 Response of combined system at different mass ratio and damping ratio for model D at const. tunning

As compared to other model,this model suppress the amplitude of vibration so high but at a small range of excitation it shows large amplitude, in order to avoid it we got the optimize damping coefficients of $\zeta_{\mathrm{a}}=0.32$.

\section{g. Comparisons among the model:}

From the above curve, we see that the amplitude of the absorber mass is always much greater than that of the main mass. Thus the design should be able to accommodate the large amplitudes of the absorber mass. For the model(A) as shown in Figures, as the mass ratio increases amplitude of vibration decreases. As mass ratio increases the optimum damping also increases. One observation we can made from the Frequency response function's curve is the response curve becomes flatter as the mass ratio increases.

If we draw the comparison curve of all 4 model in one glance by using MATLAB plot and also using optimal parameters of all the model, we came to know that For model B to be optimum, a larger damping is required as compared to model $\mathrm{A}$ .Overall, model (C) gives better vibration suppression and also required damping in between model(A) and model (B).The parallel absorber appears to be superior to the conventional clamped absorber if acomparison is made between the response curves for a damping ratio such as $\zeta_{\mathrm{a}}=0.32$. The parallel damped vibration absorber for this ratio of $\zeta_{\mathrm{a}}$ prohibitively large amplitudes with in the operational range of the vibration absorber.

Table 5.4 Comparison of the four models at $\mu=0.25$.

\begin{tabular}{|l|l|l|l|l|}
\hline MODEL & \multicolumn{1}{|c|}{$f_{\text {tuned }}$} & \multicolumn{1}{|c|}{$\zeta_{\text {opt }}$} & \multicolumn{1}{|}{$\left(\frac{X_{1}}{X_{\text {st }}}\right)_{f_{\text {const tunning }}}$} & $\left(\frac{X_{1}}{X_{\text {st }}}\right)_{\zeta_{\text {opt }}, f_{\text {tuned }}}$ \\
\hline $\mathrm{A}$ & 0.8 & 0.27 & 6.1308 & 3.2581 \\
\hline $\mathrm{B}$ & 1.1547 & 0.378 & 4.2249 & 2.2228 \\
\hline $\mathrm{C}$ & 1.13137 & 0.3273 & 2.0743 & 2.1334 \\
\hline $\mathrm{D}$ & $0.7483(\mu=0.125)$ & 0.32 & 7.1034 & 7.3945 \\
\hline
\end{tabular}




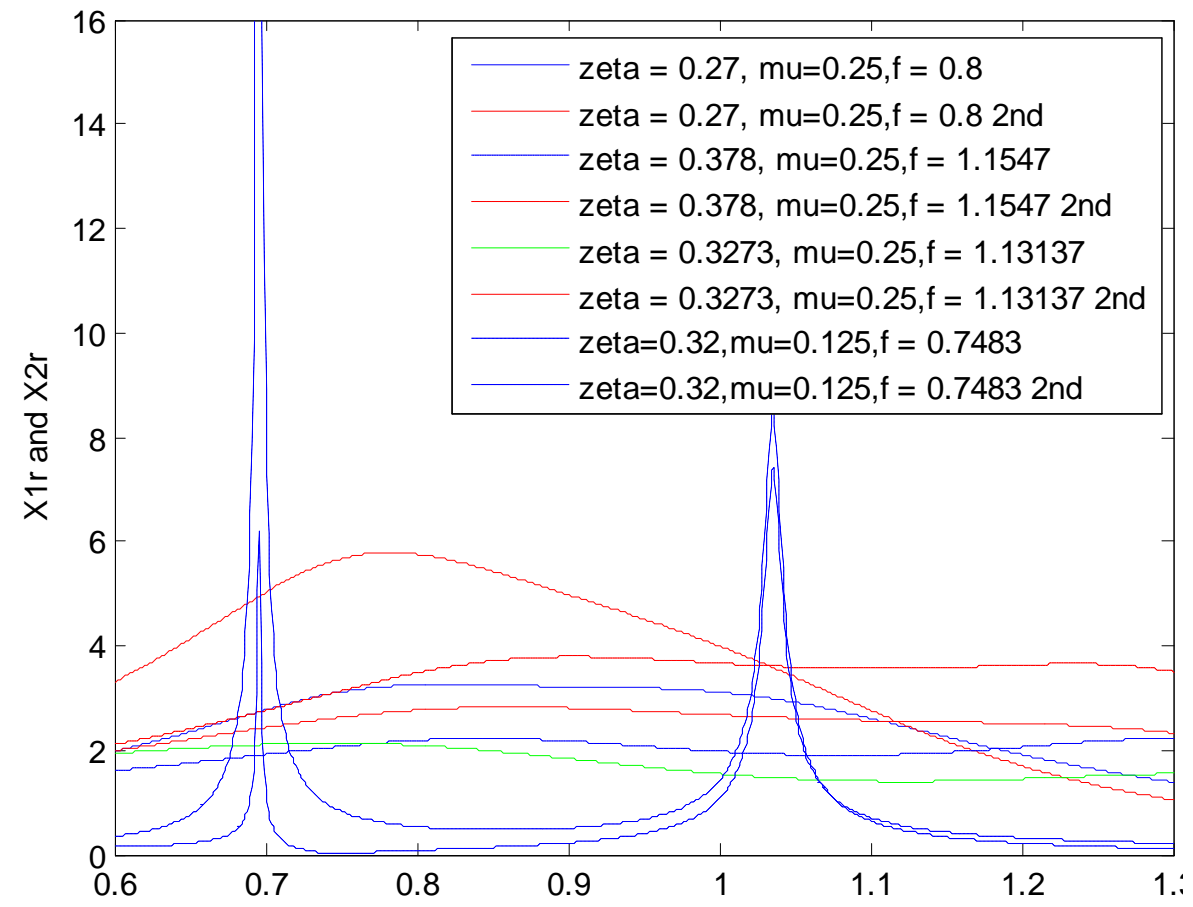

Figure V-10 Comparisons between 4 optimal model
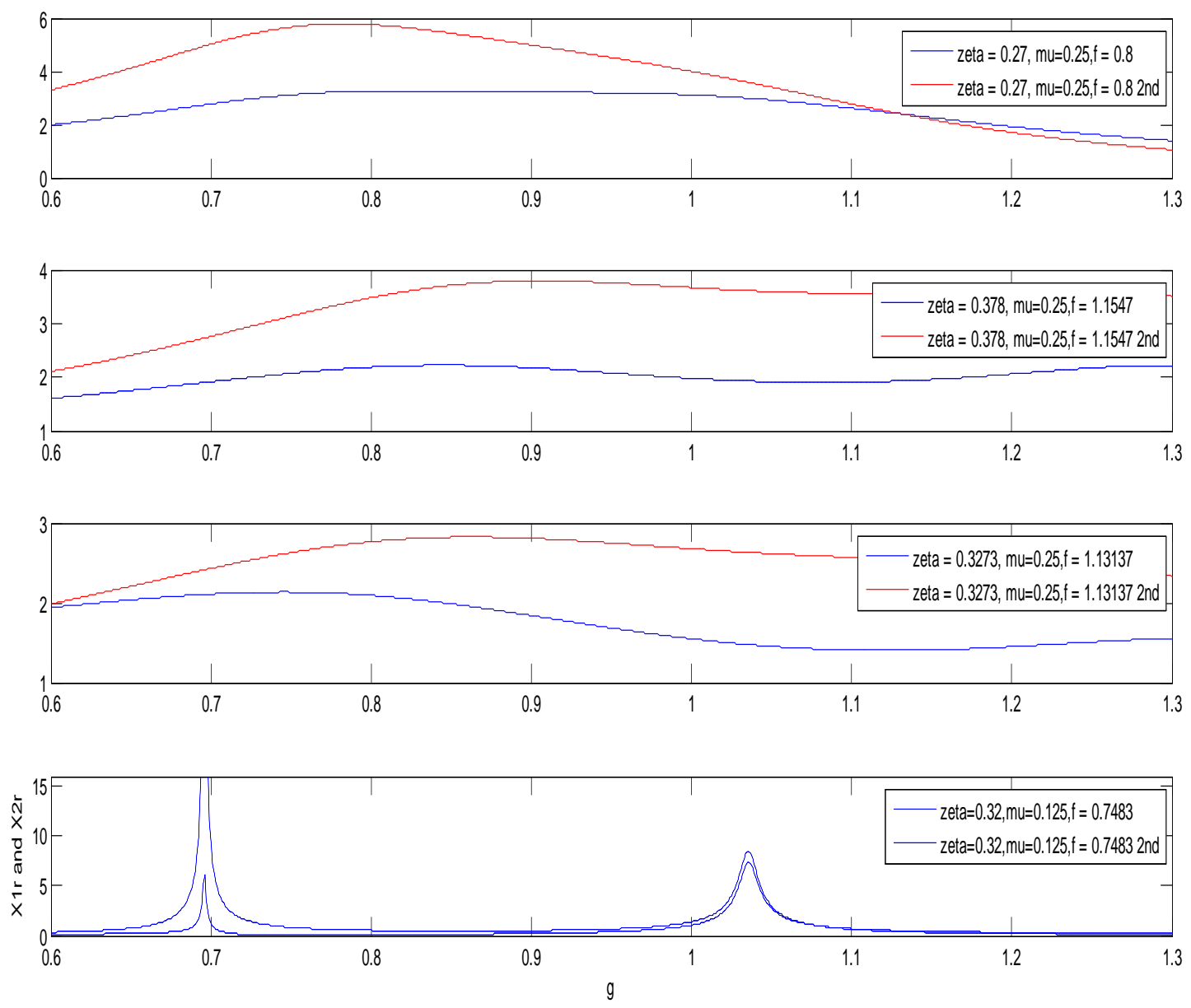

Figure V-11 Subplot Comparisons between 4 optimal model 


\section{CONCLUSION AND FUTURE SCOPE OF WORK}

\section{a. CONCLUSION}

Now a days, in construction industry wants taller and lighter structures, which are flexible with having quite low damping value. This increases failure possibilities.

Problems from serviceability point of view, Several techniques are available today to minimize the vibration of the structure, out of which concept of using of TMD is one. Effectiveness of using TMD for controlling vibration of structure. A MATLAB script was developed to optimize the different model. Following conclusions can be made from this study:

1) It has been found that the TMD can be successfully used to control vibration of the structure.

2) TMD used effectively in reducing the displacement responses of structures with low damping ratios . But, it is less effective for structures with high damping ratios (14).

3) Applying the two earthquake loadings, first is the one corresponding to compatible time history as per spectra of IS-1894(Part -1):2002 for 5\% damping at rocky soil and second being the 1940 El Centro Earthquake it has been found that increasing the mass ratio of the TMD decreases the displacement response of the structure.

b. Further Scope for study

1) Both the structure and Damper model considered in this study are linear one; this provides a further scope to study this problem using a nonlinear model for TMD as well as for structure.

2) The model considered here is two-dimensional, which can be further studied to include 3dimensional structure model.

3) Further scope, also includes studying the possibility of constructing Active TMD.

\section{REFERENCES}

[1] Timoshenko (1955). ॥Vibration problems in Engineeringll. S Van to strendCo.Inc.NewJersy. $\quad 3 r d$ Edition,.p.p.324-368.

[2] S.S. Rao (2003). \|Mechanical Vibrationll.4th edition prentice, Hall.p.p 611-613

[3] Frahm (1909) - -H.,Device for damping vibrations of bodies\|U.S. Patent No. 989958,.

[4] Ormondroyd, J. and Den Hartog, J.P.(1928)-Theory of the dynamic vibration absorberll, Transactions of the American Society of Mechanical Engineers $\|$ Vol. 50, 9-22.
[5] Brock, J. E.(1946)—A note on the damped vibration absorberlJJournal of Applied Mechanics,Vol. 68,A-284

[6] Kefu liu, jieliu.(2005)-The damped dynamic vibration absorbers:revisited and new resulttIJournal of Sound and Vibration 284 1181-1189.

[7] S.G. Kelly(2000).\| Fundamentals of Mechanical Vibrationsll.2nd ed., McGrawHill, Boston

[8] A. J. Sheth, S. S. Pathan(2012)-Identification of system parameters using tuned vibration absorber for capturing system dynamicsIIJREAS Volume 2, Issue 2 ISSN: 2249-3905 .

[9] Kefu Liu, Gianmarc Coppola (2010) Optimal design of damped dynamic vibration absorber for damped primary systems $\|$ Canadian society for mechanical engineering, 34, 119-135.

[10] A. Baz (1998), - Robust control of active constrained layer dampingl Journal of Sound and Vibration 211 pp467-480.

[11] A. Baz, (2000) - Spectral finite element modelling of wave propagation in rods using active constrained layer dampinglJournal of Smart Materials and Structures9 pp372-377.

[12] A. Chattopadhyay, Q. Liu, H. Gu, (2000) Vibration reduction in rotor blades using active composite box beaml American Institute of Aeronautics and Astronautics Journal 38 pp1125-1131.

[13] Alexander Nicholas A, Schilder Frank(2009) -Exploring the performance of a nonlinear tuned mass damperll Journal of Sound and Vibration 319 pp 445-462

[14] Alli H, Yakut O.(2005)—Fuzzy slidingmode control of structures\|Engineering Structures; 27(2)

[15] Barkana I. (1987) —Parallel feed forward and simplified adaptive controll International Journal of Adaptive Control and Signal Process;1(2):pp95-109.

[16] Barkana I. (2005)-Gain conditions and convergence of simple adaptive controll Internat J Adapt Control Signal Process;19(1):pp13-40.

[17] Barkana I, Kaufman H.(1993)-Simple adaptive control of large flexible space structuresll. IEEE Trans Aerospace Electron System; 29(4).

[18] Bitaraf Maryam, Ozbulut Osman E,Hurlebaus Stefan(2010) - Application of semi-active control strategies for seismic protection of buildings with MR dampersll Engineering Structures. 
[19] BlekhermanA.N(1996) -Mitigation of response of high-rise structural systems by means of optimal tuned mass damper\| Eleventh world conference on Earthquake Engineering paper no-89.

[20] BroganWL.(1991) -Modern control theory. Englewood Cliffs (NJ)\|PrenticeHall.

[21] Casciati F, Magonette G, Marazzi F. (2006)-Technology of semi-active devices andapplications in vibration mitigation. Chichester\| Wiley \& Sons.

[22] Chang, C. C., and Yang, H. T. Y. (1995). -Control of buildings using active tuned mass dampers.\| J. Eng. Mech., 121(3), 355366.

[23] Chen Genda,WuJingning(2001) -Optimal placement of multiple tuned mass dampers for seismic structures\| Journal of Structural Engineering, Vol. 127, No. 9

[24] Choi KM, Cho SW, Jung HJ, Lee IW. (2004) - Semi-active fuzzy control for seismic response reduction using magnetorheological dampers\| Earthquake Engineering Structural Dynamics;33

[25] 17) ChouwNawawi(2004) -Behaviour of soil-structure system with tuned mass dampers during near-source earthquakesll. Thirteenth world conference on Earthquake Engineering paper no. 1353

[26] Clark J. Allen(1988).\|Multiple passive TMDs for reducing earthquake induced building motionll. Proceedings of ninth world conference on Earthquake Engineering Tokyo Kyoto Japan, Vol.5

[27] D. Garg, G. Anderson,(2000) - Research in active composite materials and structures: an overviewll, Proceedings of the SPIE Seventh International Symposium on Smart Structures \& Materials, pp. 2-12.

[28] Den Hartog, J. P. (1947).\| Mechanical vibrationsll. McGraw-Hill, New York, N.Y.

[29] Dyke SJ, Spencer BF.(1996)-Seismic response control using multiple MR dampers. In 2nd international workshop on structural controlll. Hong Kong University of Science and Technology Research Centre.

[30] Garg Devendra P, Anderson Gary L(2003) -Structural vibration suppression via active/passive techniques\| Journal of Sound and Vibration 262 pp 739-751

[31] Ghosh A, Basu B(2004) -Effect of soil interaction on the performance of tuned mass

[32] dampers for seismic applications\| Journal of Sound and Vibration 274 pp 1079-1090
[33] Guo Y.Q, Chen W.Q(2007) -Dynamic analysis of space structures with multiple tuned mass dampers\| Engineering Structures 29 ,pp3390-3403

[34] Housner G. W,Bergman L. A, and Caughey T. K(1996) - Structural control: past, present, and future\| Journal of Engineering Mechanics, Vol.123, No.9,Paper No. 15617.

[35] Huang W, Gould PL, Martinez R, Johnson GS.(2004)-Non-linear analysis of a collapsed reinforced concrete chimney.\| Earthquake Engineering Structural Dynamics;33(4):pp485-98.

[36] Hurlebaus S, Gaul L. (2006)-Smart structure dynamics. Mechanical System Signal Process॥; 20:pp255-81.

[37] Inaudi, J. A. (1993). "Active isolation and innovative tuned mass dampers for vibration reduction," $\mathrm{PhD}$ dissertation, University of California, Berkeley, California.

[38] Inaudi J. A. (1997) -Modulated homogeneous friction: a semi-active damping strategy\| Earthquake Engineering Structural Dynamics; 26(3):pp361-76.

[39] Inaudi, J. A., and De la Llera, J. C. (1992). "Dynamic analysis of nonlinear structures using state-space formulation and partitioned integration schemes." Rep. No. UCB/EERC-92//8, Earthquake Engineering Research Centre, University of California, Berkeley, California.

[40] Inaudi, J. A., and Kelly, J. M. (1992). "A friction mass damper for vibration control." Rep. No. UCB/EERC-92//5, Earthquake Engineering Research Centre, University of California, Berkeley, California.

[41] Inaudi, J. A., and Kelly, J. M. (1993). "On the linearization of structures containing linear-friction energy dissipating devices." Proc., Damping '93, San Francisco, Calif.

[42] Jo Byung-Wan, Tae Ghi-Ho (2001) -Structural vibration of tuned mass installed three span steel box bridgell International journal of pressure vessels and piping" 78 pp "667-675.

[43] Johnson, J. G., Reaveley, L. D., and Pantelides, C. P. (2003). - A rooftop tuned mass damper frame.l Earthquake Engineering Structural Dynamics,32(6),pp965-984.

[44] Jung HJ, Choi KM, Spencer BF, Lee IW.(2006) -Application of some semiactive control algorithms to a smart baseisolated building employing MR dampersll. Structural Control Health Monitoring 13:pp693-704. 
[45] K. Cunefare,(2000) - State-switched absorber for vibration control of pointexcited beamsll, Proceedings of ASME International Mechanical Engineering Conference and Exposition, Vol. 60, pp. 477-484

[46] K. Cunefare, S. De Rosa, N. Sadegh, (2001) G. Larson, - State switched absorber/damper for semi-active structural controll, Journal of Intelligent Material Systems and Structures 11 pp300-310.

[47] Kaynia, A.M., Veneziano, D. and Biggs, J.,(1981) "Seismic Effectiveness of Tuned Mass Dampers", Journal of Structural Division Proceedings of ASCE, (I07) T8, Paper no. 16427.

[48] Kerber F, Hurlebaus S, Beadle BM, StöbenerU(2007). - Control concepts for an active vibration isolation systemll. Mechanical System Signal Process21:pp3042-59.

[49] Kitamura, H., Fujita, T, Teramoto, T, and Kihara, H. (1988). "Design and analysis of a tower structure with a tuned mass damper." Proceedings of 9th World Conference on Earthquake Engineering Vol. VII, Tokyo, Japan.

[50] Kwok K.C.S(1995) -Performance of tuned mass dampers under wind loads\| Engineering Structures, Vol. 17, No. 9, pp. 655 67

[51] Lee CC.(1995)-Fuzzy logic in control system: fuzzy logic controller part I and part II.\| IEEE Trans System Man Cybern;20:pp404-18.

[52] Lee Chien-Liang, ChenYung-Tsang(2006) -Optimal design theories and applications of tuned mass dampersll. Engineering Structures 28 pp 43-53

[53] Li, C. (2002). - Optimum multiple tuned mass dampers for structures under the ground acceleration based on DDMF and ADMF.\| Earthquake Engineering Structural Dynamics,31(4),pp 897-919.

[54] Li, C. (2003). -Multiple active-passive tuned mass dampers for structures under the ground acceleration.॥ Earthquake Engineering Structural Dynamics,32(6),pp949-964.

[55] Lin Chi-Chang, Lu Lyan-Ywan, Lin GingLong(2010) - Vibration control of seismic structures using semi-active friction multiple tuned mass dampers\| Engineering Structures.

[56] Li Hua-Jun, Hu Sau-Lon James(2002) -Tuned Mass Damper Design for Optimally Minimizing Fatigue Damage\|
Journal of Engineering Mechanics, Vol. 128, No. 6

[57] Luft, R. W. (1979). —Optimal tuned mass dampers for buildings.| Journal of Structural Division, 105(12), pp2766-2772.

[58] McNamara, R. J. (1977) "Tuned mass dampers for buildings." Journal of Structural Division, 103(9), pp1785-1798.

[59] Melbourne, W.H., (1988) "Comparison of Measurements on the CAARC Standard Tall Building Model in Simulated Model Wind Flows", Journal of Wind Engineering and Industrial Aerodynamics (6) pp.73-88.

[60] Nagarajaiah, S., and Sonmez, E. (2007). - Structures with semi-active variable stiffness single/multiple tuned mass dampers.|| Journal of Structural Engineering, 133(1),pp 67-77.

[61] Nashif. A., Jones, D., and Henderson, J. (1985). - Vibration damping.\| John Wiley \& Sons, New York, N.Y.

[62] P. Huang, P. Reinhall, I. Shen, J. Yellin(2001), - Thickness deformation of constrained layer damping - an experimental evaluationl, American Society of Mechanical Engineers Journal of Vibration and Acoustics:123 pp213-223.

[63] Petersen, N. R. (1980). "Design of large scale tuned mass dampers." Structural control, H. H. E. Leipholz, cd.,NorthHolland Publishing Co.

[64] Pinkaew T, Lukkunaprasit P, Chatupote $\mathrm{P}(2003)$-Seismic effectiveness of tuned mass dampers for damage reduction of structures\| Engineering Structures 25,pp3946

[65] Roberts, J. B., and Spanos, P. D. (1985). $\|$ Random vibration and statistical linearizationll. John Wiley \& Sons, New York, N.Y.

[66] Runlin Yang, Xiyuan Zhou, Xihui Liu(2002) - Seismic structural control using semi-active tuned mass dampers Earthquake engineering and engineering vibration

[67] SadekFahim, MohrazBijan(1997) -A method of estimating the parameters of tuned mass dampers for seismic applications\|. Earthquake Engineering and Structural Dynamics Vol.26 pp 617-635

[68] Saidi I, Mohammed A.D(2007) —Optimum design for passive tuned mass dampers using viscoelastic materials\| Australian Earthquake Engineering Society Conference

[69] Sanchez E, Shibata T, Zadeh La.(1997)-Genetic algorithms and fuzzy logic systems: soft computing perspectives\|l. 
River Edge (NJ): World Scientific Publishing.

[70] Setareh, M., and Hanson, R. (1992). -Tuned mass dampers to control floor vibration from humans.".Structural Engineering.,ASCE, 118(3),741-762.

[71] ShamaliBijan, Al-DawodMohammed(2003) -Performance of a five-storey benchmark model using an active tuned mass damper and a fuzzy controllerl. Engineering Structures 25 pp 1597-1610

[72] Shimazu T, Araki H(1996) - Survey of actual effectiveness of mass damper systems installed in buildingsl. Eleventh world conference on Earthquake Engineering, Paper no.809

[73] Singh, M. P., Singh, S., and Moreschi, L. M. (2002). - Tuned mass dampers for response control of torsional buildings.\| Earthquake Engineering and Structural Dynamics,31(4), pp749-769.

[74] Sobel K, Kaufman H, Mabius L. (1982) - Implicit adaptive control for a class of MIMOsystems\| IEEE Trans Aerospace Electron System; AES-18(5).

[75] Spencer BF, Dyke SJ, Sain MK, Carlson JD.(1997) - Phenomenological model of a magnetor-heological damper.\| Journal of Engineering Mechanics;123(3):pp230-8.

[76] TakewakiI (2000).|ISoil-structure random response reduction via TMD-VD simultaneous usell Computer Methods in Applied Mechanics and Engineering 190, pp 677-690

[77] Trifunac, M.D, IvanovicS.S,Todorovska M.I.(2001) -Apparent periods of a building. I: Fourier analysisll. Journal of Structural Engineering 127 (5),pp 517-526.

[78] VaradarajanNadathur, Nagarajaiah Satish(2004) -Wind Response Control of Building with Variable Stiffness Tuned Mass Damper Using Empirical Mode Decomposition /Hilbert Transformll Journal of Engineering Mechanics, Vol. 130, No. 4 ,pp451-458

[79] Vickery, B.J. and Davenport, A.G.,( 1970), -An Investigation of the Behaviour in Wind of the Proposed Centrepoint Tower in Sydney, Australiall, Engineering Science Research. Dept., BLWT-70, University of Western Ontario.

[80] W. Liao, K. Wang, (1998) - Characteristics of enhanced active constrained layer damping treatments with edge elementsll, Part 1: Finite element model and experimental validation, American Society of Mechanical Engineers Journal of Vibration and Acoustics 120 886-893.
[81] Warburton, G. B. (1982). "Optimum absorber parameters for various combinations of response and excitation parameters." Earthquake Engineering and Structural Dynamics, Vol. 10,pp381-491.

[82] Wardlaw, R.L. and Moss, G.F.,(1970) "A Standard Tall Building Model for the Comparison of Simulated Natural Winds in Wind Tunnels", CAARC, CC-662 MTech 25.

[83] Webster, A. c., and Vaicaitis, R. (1992). "Application of tuned mass dampers to control vibrations of composite floor systems." Engineering. Journal, 29(3), pp116-124.

[84] Williams SR.( 2004)—Fault tolerant design for smart damping systemsll. St. Louis (MO): Department of Civil Engineering, Washington University.

[85] Wong K.K.F(2008) - Seismic Energy Dissipation of Inelastic Structures with Tuned Mass Dampersl Journal of Engineering Mechanics, Vol. 134, No. 2

[86] Wong, K. K. F., and Yang, R. (1999). -Inelastic dynamic response of structures using force analogy method.ll Journal of Engineering Mechanics, 125(10),pp11901199.

[87] Xu, K., and Igusa, T. (1992). - Dynamic characteristics of multiple tuned mass substructures with closely spaced frequencies.\| Earthquake Engineering and Structural Dynamics,21(12), pp1059-1070.

[88] Y. Jeung, I. Shen, (2001) - Development of an iso-parametric, degenerate constrained layer element for plate and shell structuresll, American Institute of Aeronautics and Astronautics Journal 23 pp280-284.

[89] Y. Liu, Y.K. Wang (2000), -Activepassive hybrid constrained layer for structural damping augmentationll, American Society of Mechanical Engineers Journal of Vibration and Acoustics122 pp254-262.

[90] Yan, N., Wang, C. M., and Balendra, T. (1999). - Optimal damper characteristics of ATMD for buildings under wind loads.l Journal of Structural Engineering,125(12), pp1376-1383.

[91] Yan G, Zhou LL. (2006)-Integrated fuzzy logic and genetic algorithms for multiobjective control of structures using MR dampersll. Journal of Sound and Vibration;296(1-2):pp368-82

[92] Ying H. (2000)-Fuzzy control and modelling: analytical foundations and applications.| Wiley-IEEE Press. 
[93] Zhu S.J , Zheng Y.F, Fu Y.M.(2004).\|Analysis of non-linear dynamics of a two-degree-of-freedom vibration system with nonlinear damping and nonlinear spring $\|$ Journal of Sound and Vibration 271,pp 15-24

" International Journal of Engineering Research and Applications (IJERA) is UGC approved Journal with Sl. No. 4525, Journal no. 47088.

S. Pani. "Review of an Effective Dynamic Vibration Absorber for a Simply Supported Beam and Parametric Optimization to Reduce Vibration Amplitude." International Journal of Engineering Research and Applications (IJERA) 7.7 (2017): 49-77. 